University of Louisville

ThinkIR: The University of Louisville's Institutional Repository

Electronic Theses and Dissertations

$5-2011$

\title{
A comparison of two social skills interventions for children with autism spectrum disorder.
}

Grace Mathai

University of Louisville

Follow this and additional works at: https://ir.library.louisville.edu/etd

\section{Recommended Citation}

Mathai, Grace, "A comparison of two social skills interventions for children with autism spectrum disorder." (2011). Electronic Theses and Dissertations. Paper 918.

https://doi.org/10.18297/etd/918

This Doctoral Dissertation is brought to you for free and open access by ThinkIR: The University of Louisville's Institutional Repository. It has been accepted for inclusion in Electronic Theses and Dissertations by an authorized administrator of ThinkIR: The University of Louisville's Institutional Repository. This title appears here courtesy of the author, who has retained all other copyrights. For more information, please contact thinkir@louisville.edu. 


\title{
A COMPARISON OF TWO SOCIAL SKILLS INTERVENTIONS FOR CHILDREN WITH AUTISM SPECTRUM DISORDER
}

\author{
By \\ Grace Mathai \\ B.A Bangalore University, 1989 \\ M.A Bangalore University, 1993 \\ A Dissertation Submitted to the Faculty of the \\ College of Education and Human Development of the University of Louisville \\ in Partial Fulfillment of the Requirements \\ for the Degree of
}

Doctor of Philosophy

Department of Educational and Counseling Psychology

University of Louisville

Louisville, Kentucky

May 2011 



\section{A COMPARISON OF TWO SOCIAL SKILLS INTERVENTIONS FOR CHILDREN}

WITH AUTISM SPECTRUM DISORDER

By

Grace Mathai

B.A., Bangalore University, 1989

M.A., Bangalore University, 1993

A Dissertation Approved on

March 3, 2011

By the following Dissertation Committee:

Dissertation Director (Patrick Hardesty)

Nancy J. Cunningham

Eva Markham

Gregory R. Mancil

Monica Delano 


\section{ACKNOWLEDGEMENTS}

It is with deep gratitude that I acknowledge the many professionals, friends and family members who have supported and encouraged me in the pursuit of higher learning and contribution to research. The culmination of this research project was possible through the unwavering support and guidance offered by my chair, Dr. Patrick Hardesty. I am grateful for his availability and mentorship in the guidance of this project. I would like to express my appreciation to committee members, Dr. Nancy Cunningham for her helpful suggestions and attention to detail in review of this work and Drs. Eva Markham, Monica Delano, and Rich Mancil for their insightful comments and their depth of knowledge in the field of Autism that was made available to me.

This work would not have been possible if it was not for the opportunity I had to work with children on the Autism Spectrum at the STAR (Systematic Treatment of Autism and Related Disorders) program at the University of Louisville. I am exceedingly grateful to the many clinicians and researchers who inspired me through their dedication

and expertise in the field of Autism, including Dr. Lisa Ruble for the mentoring received and Dr. Lonnie Sears for his various tips on methodology.

My parents instilled in me the value of education, the faith to persevere despite odds, and that I can do all things through Christ who gives me strength. I am grateful for their vision and spiritual lending that has continued to guide me. Many thanks to my 
brothers, sisters, family, and friends for cheering me on and celebrating every victory with me.

Finally, I know that I could never have embarked on this journey and come this far without the untiring support of my husband Mathews and the unconditional love bestowed by Snowball. 


\section{ABSTRACT \\ A COMPARISON OF TWO SOCIAL SKILLS INTERVENTIONS FOR CHILDREN WITH AUTISM SPECTRUM DISORDER \\ Grace Mathai \\ March 3, 2011}

Social reciprocity deficits are a core feature of the autism spectrum disorders (ASD) and a major source of impairment regardless of cognitive or language ability (Carter, Davis, Klin, \& Volkmar, 2005). Since these impairments do not naturally remit with age, it is critical to intervene as early as possible to offset potential risk factors (Tantum, 2003). Group training approaches provide children with teaching opportunities with other children and allow for the direct instruction of skills within a structured environment (Bellini, Peters, Benner, \& Hopf, 2007). Research in social skills group research has increased, but several questions remain.

This study evaluated the outcome of a social skills curriculum for 37 children between the ages of 8 to 14 with a diagnosis of ASD within two different treatment contexts, the camp and clinic model. The camp model simulates a natural setting in which children with ASD spend 5 hours each day for 10 days where social skills are taught through engaging activities and interactions with peers both typical and with ASD. The clinic model, on the other hand, is a one hour a week session spread over 10 to 12 weeks where social skills are taught and practiced while parents observe through a one-way mirror and are trained on the intervention methods. Both clinic and camp model 
treatments are then compared with a third group who experience both treatments within the clinic and camp setting.

Results show that the combined context had the highest treatment effects, followed by the camp model and, finally, the clinic model. Analysis of covariance did not indicate the groups differ from each other significantly in terms of treatment gains. The implications of these results are discussed in terms of translation of research into clinical practice, use of appropriate outcome measures, and generalization of skills through parent training and utilization of training programs within the natural context. While the intervention and results are promising, replication with larger samples and use of a control group are needed. 


\section{TABLE OF CONTENTS}

ACKNOWLEDGEMENTS............................................................

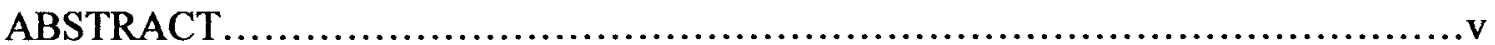

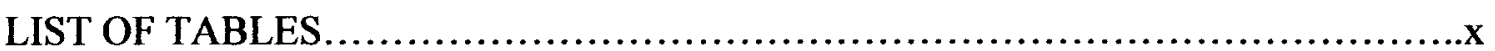

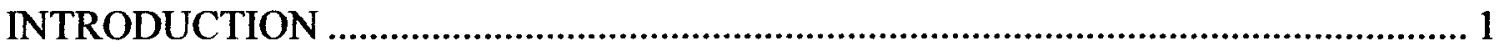

Study Overview

The following research questions were addressed ......................................................... 5

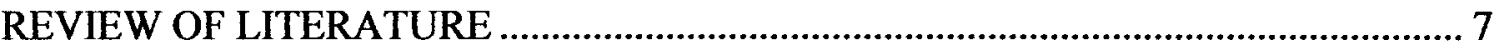

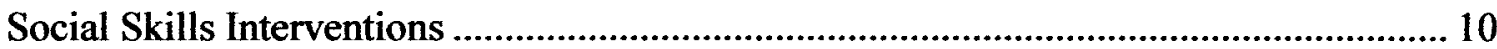

Essential Ingredients for a Social Skills Curriculum .................................................. 11

Teaching Strategies Employed in this Study .......................................................... 14

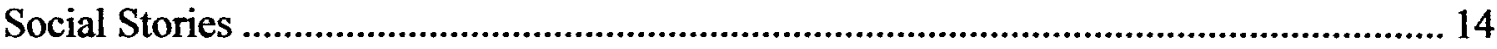

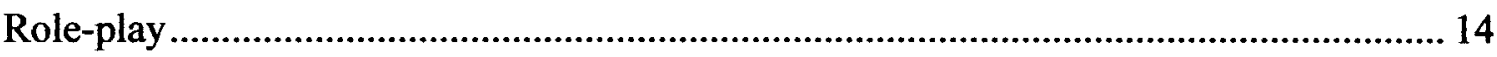

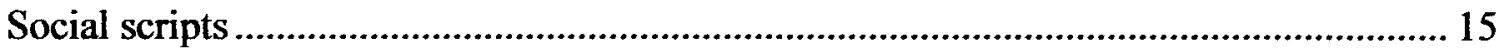

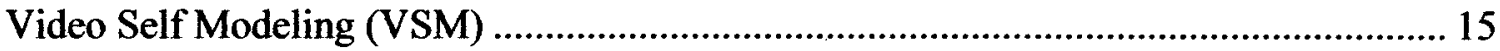

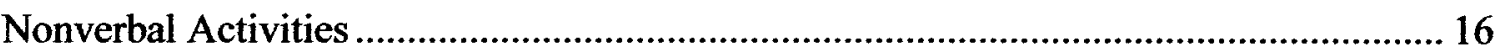

Group Versus Individual Social Skills Training .................................................. 16

Review of Social Skills Group Research .......................................................... 17

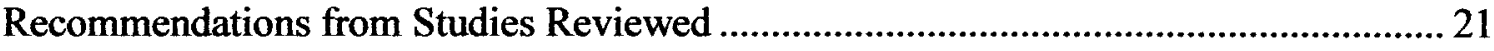

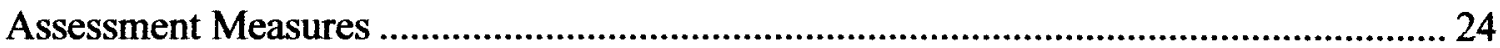




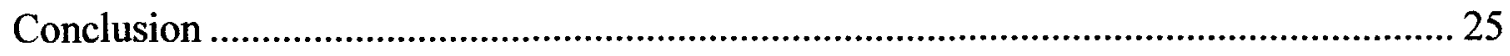

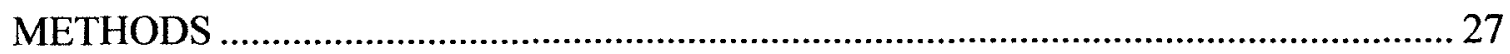

Social Skills Curriculum and Teaching Strategies........................................................ 27

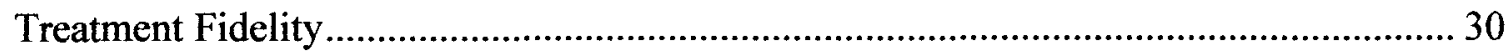

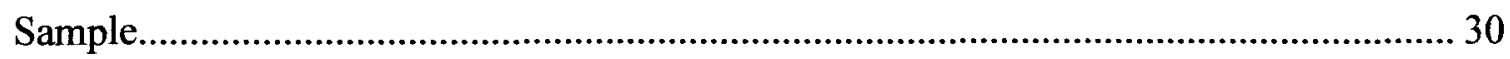

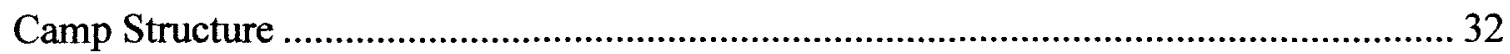

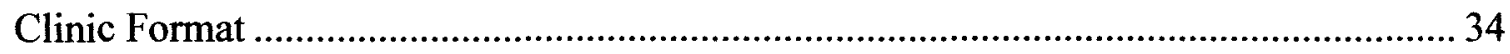

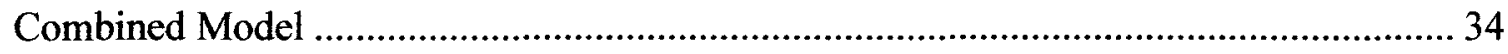

Instrumentation

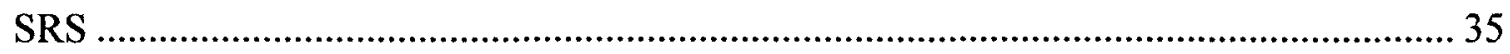

TSSA

$\mathrm{ABC}$

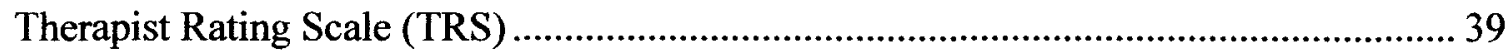

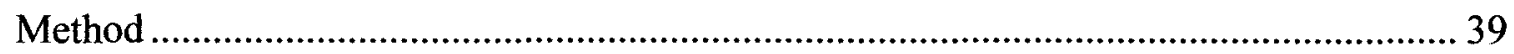

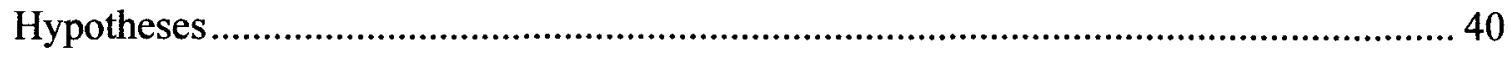

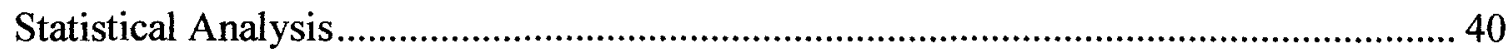

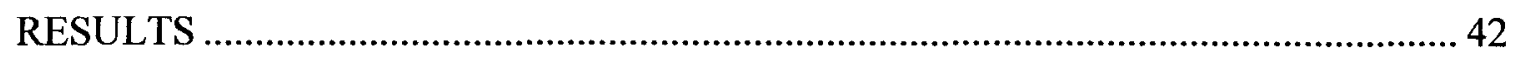

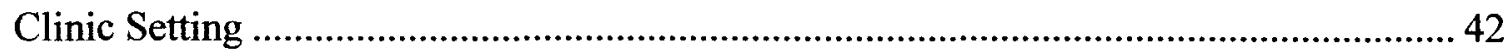

Pre and Post Analysis of Problem Behaviors ................................................................. 43

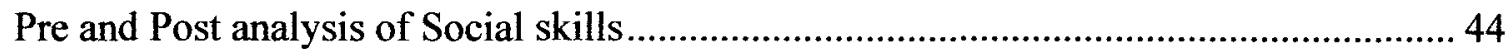

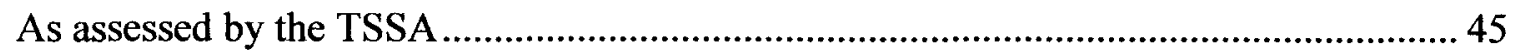

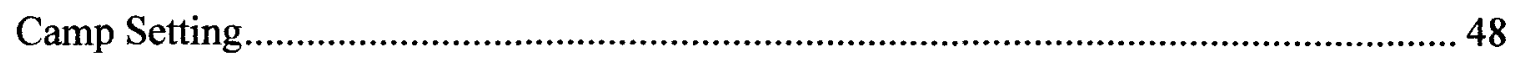

Pre and Post analysis of problem behaviors: ................................................................ 48 


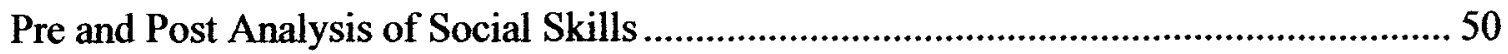

Clinic and Camp Setting (Combined Condition) ........................................................ 54

Pre and Post Analysis of Problem Behaviors ………….............................................. 54

Pre and Post analysis of Social Skills ........................................................................ 56

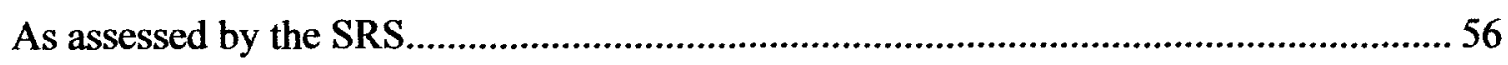

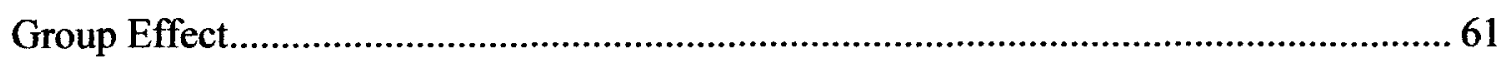

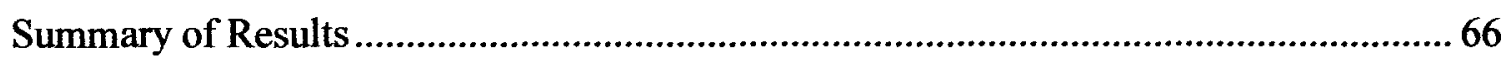

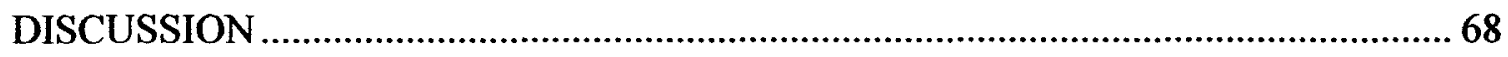

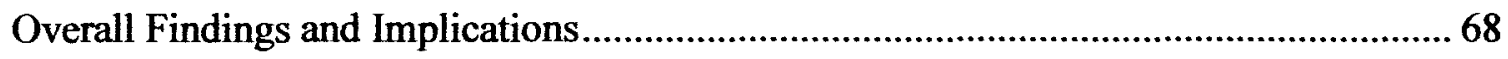

Relationship of Results to Generalization Through Parent Training............................... 72

Relationship of Results to Use of Natural Contexts ........................................................ 74

Relationship of Results to Valid Outcome Measures …………........................................ 76

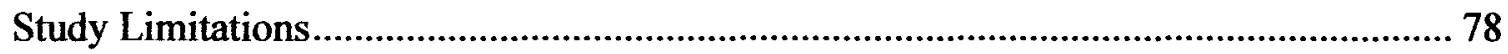

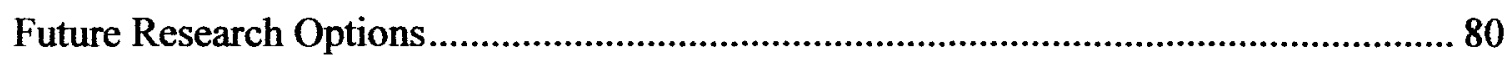

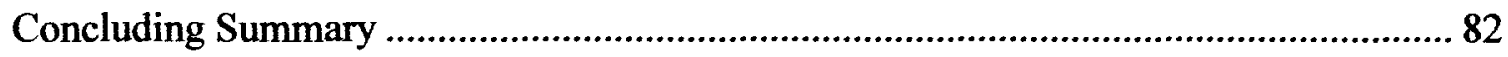

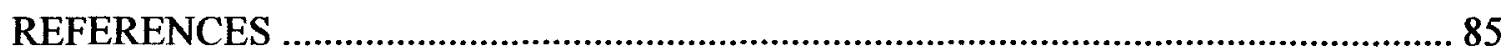

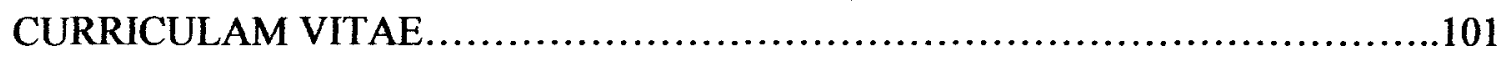




\section{LIST OF TABLES}

TABLE

PAGE

1. Example of 10-day Social Skills Instruction Program ...........................28

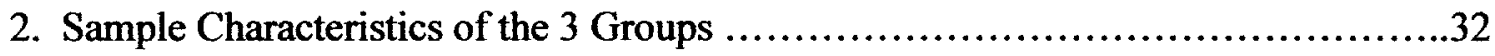

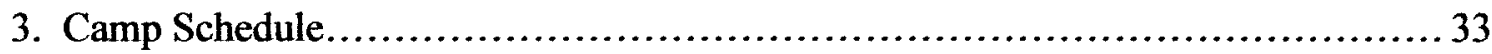

4. Paired Sample Statistics of Behavior Scores in the Clinic Condition................ 43

5. Paired Sample Statistics of SRS Scores in the Clinic Condition....................45

6. Paired Sample Statistics of TSSA Scores in the Clinic Condition................... 46

7. Paired Sample Statistics of TRS Scores in the Clinic Condition....................47

8. Paired Sample Statistics of ABC Scores in the Camp Condition....................49

9. Paired Sample Statistics of SRS Scores in the Camp Condition.....................50

10. Paired Sample Statistics of TSSA Social Skills scores in the Camp Condition.......52

11. Paired Sample Statistics of TRS Scores in the Camp Condition...................54

12. Paired Sample Statistics of ABC and TSSA1 Scores in the Combined Condition... 55

13. Paired Sample Statistics of SRS scores in the Combined Condition................57

14. Paired Sample Statistics of TSSA scores in the Combined Condition................59

15. Paired Sample Statistics of TRS scores in the Combined Condition.................61

16. ANCOVAs Demonstrating the Effect of Group on the Dependent Variables........62

17.Summary of Profile Plots Showing Effect of Group on the Dependent Measures.....65 


\section{CHAPTER 1}

\section{STATEMENT OF THE PROBLEM}

\section{Introduction}

Social reciprocity deficits are a core feature of the autism spectrum disorders (ASD) and have profound adverse ramifications regardless of cognitive or language ability (Carter, Davis, Klin, \& Volkmar, 2005). Social impairments and their effects do not naturally remit with maturation and may actually increase as the child approaches adolescence due to the complexity of the social milieu, the child's own awareness of their social differences (Tantum, 2003), and an increasing discrepancy between social abilities of same age peers and the adolescent with ASD. Very often, children and adolescents with ASD are at an increased risk for peer rejection and social isolation (Chamberlain, 2001), academic and occupational underachievement (Howlin 2000), and mood and anxiety problems (Myles, 2003; Tantum, 2003). Thus, it is critical to intervene as early as possible to offset these potential risk factors and develop interventions that improve young children's peer-related social competence and social-cognitive problem-solving skills.

Because children with ASD fail to develop appropriate social skills and often lack opportunities for learning through positive peer interactions, providing explicit training is essential. Training that occurs in a group format may be more relevant and preferred for many settings. Group training approaches provide children with teaching opportunities with other children and allow for the direct instruction of skills within a structured 
environment, which often does not take place explicitly in school settings (Bellini, Peters, Benner, \& Hopf, 2007). Finally, group training may utilize resources more effectively by allowing autism specialists, who are often limited in number in outpatient and school settings, to work with many children on the spectrum simultaneously. Interest in the group social skills interventions has increased, and many examples now available in the literature (e.g., Barnhill, Cook, Tebbenkamp, \& Myles, 2002; Barry et al., 2003; Bauminger, 2007; Crager \& Horvath, 2003; Hwang \& Hughes, 2000; Kroeger,_Schultz, \& Newsom, 2007; Lopata, Thomeer, Volker, \& Nida, 2006; Ruble, Willis, \& Crabtree, 2008; and Tse, Strulovitch, Tagalakis, Meng, \& Fombonne, 2007).

A main issue faced by clinicians is the provision of social skills group interventions that are effective and data-driven (Ruble et al., 2008). Despite the growing interest, importance, and need for group social skills training, empirical support is mixed and limited at best. For example, Gresham, Sugai, and Horner (2001) conducted a metaanalysis of social skills training programs for children (not with ASD) and produced mixed results. They reported that effect sizes ranged greatly from ineffectual to highly effective. For individuals with ASD, White, Koenig, and Scahill, (2007) reviewed the literature for group social skills interventions and found very little empirical support, a finding concluded by others (Bellini et al., 2007).

In contrast to the aforementioned conclusions on effectiveness of social interventions, McConnell (2002) reviewed 55 studies for young children with ASD and deduced a different conclusion. He identified several effective social skills interventions and concluded that children with ASD can benefit from social skills programming. 
Because of the mixed results on the effectiveness of social skills interventions, perhaps a useful approach is to focus on the specific and potential active ingredients within a successful program. From their review of the literature, Gresham, Sugai, and Horner (2001) concluded that (a) social skills training should be implemented more frequently and more intensely than what is typically implemented and 30 hours of instruction spread over 10 to 12 weeks may not be sufficient; (b) plans for adequate maintenance and generalization of skills should be included; (c) social skills teaching strategies should take into account the type of skill deficit presented (e.g., if the child is experiencing skill acquisition deficits, then intervention strategies are designed to teach new skills, and if the child is experiencing performance deficits, then intervention strategies are designed to enhance the performance of existing skills); and (d) treatment integrity should be monitored. White et al. (2007) also reported many promising intervention strategies such as making social rules clear and concrete and modeling age appropriate initiation strategies. Finally, McConnell divided social skills interventions into five useful categories for reviewing instructional approaches that included the use of (a) environmental modifications, (b) child-specific interventions, (c) collateral skills interventions, (d) peer-mediated interventions, and (e) comprehensive interventions.

According to McConnell (2002), environmental modifications involve changes to the physical and social environment that promote social interactions between children with ASD and their peers. Child-specific interventions involve the direct instruction of social behaviors, such as initiating and responding. Collateral skills interventions involve strategies that promote social interactions through training in related skills, such as play, behavior, and language, rather than training specific social behaviors. Improvement in 
social skills also should generalize to other areas specifically problem behaviors (collateral behaviors) that occur as a result of social or communication deficits. Hence, pre- and post- measures of problem behaviors also can indicate treatment effectiveness. Peer-mediated interventions involve training typical peers to direct and respond to the social behaviors of children with ASD. Finally, comprehensive interventions involve social skills interventions that combine two or more of the above mentioned intervention categories.

\section{Study Overview}

Given the mixed results of social skills training, as mentioned above, and considering the recommended factors that could enhance the effectiveness of these trainings, the primary focus of this study is to describe strategies to develop, implement, and evaluate a comprehensive social skills group intervention for children with ASD between the ages of 8 to 14. Keeping in mind the specific social skills deficits associated with ASD and recommendations from the literature, a social skills training manual was developed based on the experience of having run more than 15 social skills groups conducted as part of an outpatient clinic-based program that included more than 60 children. Therefore, the procedures are able to be feasibly applied within a communitybased outpatient treatment, camp, or school setting. The intervention format targeted specific skill deficits, while using the recommended intervention strategies previously reviewed (White et al., 2007).

The effectiveness of the developed social skills training manual was studied within two different settings. The first was the clinic setting where four to five children with ASD at a time were taught within a group format by trained professionals for an 
hour a week spread over 12 weeks. An integral part of the clinic model was that parents were simultaneously trained in social skills instructional methods and viewed the group process through a one-way mirror. The primary purpose was to generalize skills acquired in the session through parents to different social contexts outside the clinic. Thus, parent training within this model was intended to intensify social skills training and facilitate generalization to other contexts.

The second was the camp setting, where about 25 children with ASD were divided into five different groups based on language and cognitive functioning. Camp was held over the summer for 10 days and children attend for 5 hours each day. The first hour and a half was spent on teaching the skill of the day, the remainder is spent on fun group interactional activities where children were encouraged to use the various skills learnt and are reinforced accordingly. The camp also incorporated typical peers trained to interact with their ASD counterparts. Parents were given information about the various skills targeted but did not observe the instructional process. Camp was, therefore, a natural milieu where children with ASD were trained and social interactions supported, facilitated and encouraged by trained professionals for 5 hour periods across 10 days.

The following research questions were addressed

1. Will the social skills intervention improve social functioning of children with ASD applied within the clinic model?

2. Will the social skills intervention improve social functioning of children with ASD applied within the camp model?

3. Will the social skills intervention improve social functioning of children with ASD who attend both the clinic and camp model? 
4. Will the social skills intervention improve collateral behaviors not specifically targeted for children with ASD in the clinic only, camp only, and combined clinic and camp models?

This study is unique to prior studies in social skills training, in that an environmentally modified setting, such as a camp structure, with use of a maualized social skills curriculum and typical peers trained to interact with children on the spectrum, has not been studied before. The camp model incorporates environmental modifications and facilitates the generalization of skills through the day for 10 successive days. This model is then compared with the traditional clinic model, with an added component of parent training to facilitate transference of skills to other settings. The combined model will predict if increase in treatment will affect outcome measures. The purpose of this study is to close the research to practice gap evidenced in prior studies and outline a successful social skills intervention program for children on the autism spectrum. 


\section{CHAPTER II \\ REVIEW OF LITERATURE}

\section{Overview}

Among children with disabilities, those with autism spectrum disorders (ASD), in particular, demonstrate a number of significant social behavior deficits such as lack of social reciprocity, initiating for social reasons, and responding naturally toward social situations (Dawson, Meltzoff, Osterling, Rinaldi, \& Brown, 1998; Hauck, Fein, Waterhouse, \& Feinstein, 1995; National Research Council, 2001). Associated with the social deficits are problem social behaviors that include negative reactions to social situations with aggression, tantrums, destruction, or taking of materials (Eaves \& Ho, 1997; Scattone, Wilczynski, Edwards, \& Rabian, 2002; Schriebman, 1988; Simpson, Myles, Sasso, \& Kamps, 1997).

Simply stated, social skill deficits are a defining feature of ASD (Weiss \& Harris, $2001)$ and, if left untreated, will likely persist across time and limit not only social engagement but also other important skills such as cognition and language development (Rogers, 2000). Very often, intervention may improve communication and some behavior problems such as repetitive behaviors (Piven, Harper, Palmer, \& Amdt, 1996). However social difficulties continue to remain, often interfering with academic and vocational success (Howlin \& Goode, 1998). Interpersonal relationships with family members and friends may suffer. Additionally, the ability to obtain and maintain employment may be difficult. Successful employment depends largely on the ability to get along with others. 
In fact, deficiencies in social skills are much more likely to cause termination of employment than are nonsocial factors (Jackson, Jackson, \& Bennett, 1998). Highfunctioning autistic children, in particular, are more aware of their differences from their typical peers. As they mature and it becomes critically important to fit in, they may find themselves rejected, isolated and bullied. Thus they can be at risk for low self-esteem, depression and anxiety disorders (Tse, Strulovitch, Tagalakis, Meng \& Fombonne, 2007). Without targeted interventions designed to address natural context social demands, children with ASD are likely to exhibit problematic social behavior and to become increasingly socially withdrawn (Eaves \& Ho, 1997; Weiss \& Harris, 2001).

Social isolation is one of the dominant characteristics of children with ASD. Since a main social deficit involves difficulty with interpersonal interactions and reciprocity, several resultant behaviors serve to maintain the function of social avoidance. These behaviors either isolate them within their natural context or restrict the delivery of intervention services to less integrated settings, further exacerbating delays in social competence (Stichter, Randolph, Gage, \& Schmidt, 2007). As children with ASD are increasingly included in general education classrooms, their peer-related social skills deficits become more apparent, resulting in increased isolation and peer rejection (Fisher $\&$ Meyer, 2002). If left untreated, social isolation paired with deficits in social competence negatively impact the quality of their lives and also lead to deficits in other developmental areas such as language and cognition (Rogers, 2000).

Individuals with ASD report feeling lonelier and having poorer quality friendships (Capps, Sigman, \& Yirmiya, 1996) than their typically developing classmates (Bauminger \& Kasari, 2000). Sigman and Rushkin (1999) noted that only $27 \%$ of 
children with ASD in their sample had a best friend compared to $41 \%$ of children with developmental disabilities. These specific deficits in interpersonal relationships, use of play and leisure time, and coping skills distinguish children with autism from children with other developmental disorders (Freeman, Del'Homme, Guthrie, \& Zhang, 1999; Rodrigue, Morgan, \& Geffken, 1991).

Other social difficulties that individuals with ASD experience despite their cognitive or language abilities, are reading, interpreting and responding to body cues appropriately. They may have difficulty taking turns during an interaction or conversation and knowing how to select information that is relevant. They can often experience trouble selecting appropriate topics of interest and choosing topics that are right to the setting and the conversational partner, maintaining the topic for any length of time, and switching topics appropriately. In short, they often demonstrate difficulty in adjusting their communication to the needs of the person with whom they are speaking to (e.g., taking into consideration their age or interests) (Krasny, Williams, Provencal, \& Ozonoff, 2003).

Further aspects of social functioning that are affected in ASD as summarized by Koenig et al., (2009) include (1) Difficulty in the ability to identify facial expressions (Schultz et al. 2003); (2) impairment in understanding intonation or prosody of speech, the differences encountered in language, communication pragmatics, and the interpretation of gesture (Tager-Flusberg, Paul, \& Lord 2003); (3) difficulty understanding the context of the social environment (Klin, 2000); (4) poor emotional regulation skills (Konstantareas \& Stewart 2006); (5) lack of insight into the emotional components of relationships (Begeer et al., 2008); (6) difficulty or lack of ability to take the perspective of others (Baron-Cohen, Tager-Flusberg, \& Cohen, 2000); and (7) 
Inability to self-monitor behavior (Koegel \& Koegel 1995). And finally, a key element of effective social functioning remarkably absent in ASD is the fluid application of one's knowledge and behavior to reciprocal interaction with others (Klin, Jones, Shultz \& Volkmar, 2003).

Educators, clinicians, and school administrators agree that identification and intervention of social skills deficits should be a focus of instruction if children with ASD are expected to achieve success and independence (Brown, Odom \& Conroy, 2001; US Department of Education, 2003). In fact, according to Howlin, Mawhood, \& Rutter (2000), if these social deficits are left untreated, they tend to increase rather than diminish with age.

\section{Social Skills Interventions}

Research has demonstrated a link between many strategies and improvement in areas of functioning such as IQ, joint attention, and language in children with autism (NRC, 2001; Whalen \& Schreibman, 2003). These gains are not realized for all children, under all conditions, and at the same rate. Moreover, these gains are not easy to replicate across all contexts. This issue of differentiated effects is currently characterized as the "research to practice" gap (Carnine, 1995).

Social skills intervention programs have been extensively evaluated for effectiveness and rigor, according to available evidence-based standards (Horner et al., 2005; Odom et al., 2005; Simpson, 2005). Despite the continued emphasis on evidencebased practices, current ASD literature provides no concrete insights related to specific phenotype or diagnostic subtype that can accurately predict which social competence intervention package works best for specific individuals (Borden \& Ollendick, 1994; Fein 
et al., 1999). Yet, sufficient research and analyses does exist to outline common components of effective social skills programs and the emphasis that needs to be placed on the applicability of those components for different age groups.

\section{Essential Ingredients for a Social Skills Curriculum}

Essential ingredients of a social skills curriculum as summarized by Krasny, Williams, Provencal, and Ozonoff, (2005) through their extensive review of literature on social skills intervention and programs, include a number of teaching strategies that can enhance learning in individuals with ASD and are described below. These strategies take into account the specific learning differences of individuals with ASD and their difficulties with abstract concepts involved in teaching social competence such as friendship, empathy, and kindness. Because children with ASD tend to be concrete and literal, a critical first step is to define the abstract social skill in clear and concrete terms. For example, "personal space" is defined as an arm away or a ruler away rather than too close or too far. Visually-based instruction is another example of a way to make the abstract concrete. These would include visual cues, props, and prompts to augment verbal instruction.

Transitions in activities could create some anxiety in children with ASD, and one way to offset this is to incorporate consistent routines and provide predictability. Use of visual supports, such as schedules and maintaining a consistent opening, lesson, and closing format regardless of session topic, can be helpful.

Since there is a complex interaction between social skills, cognitive, and language abilities, children with ASD not only have social challenges, but also communication and cognitive challenges as well. It is, therefore, critically important to consider the cognitive 
and language abilities of the children participating in social skills intervention and to adapt the intervention to their level as needed. One way to do this is to group children by general language ability, so that those who need extra structure, and language supports are treated together. Then, activities can be adapted, taking into consideration the levels of language support and cognitive ability of the participants within the same group.

Often Children with autism demonstrate strengths in visual processing (Quill, 1997), yet there can be diversity in their interests, preferences, and learning styles. These preferences should be evaluated and taken into consideration while teaching social skills. Different learning modalities can be included such as construction tasks, games, role plays, craft projects, gross motor activities, reading or writing tasks, and drawing or art activities. Children can practice social skills while working in dyads, small groups, or large groups.

The desire to attend to the interests of others, get to know others, and do things for others is often impaired (Baren-Cohen \& Wheelwright, 2004). One way to facilitate the development of perspective taking skills is to ensure that activities prescribed within the curriculum are focused on the "other". Nothing that can be done in a pair or group is ever done alone. Facilitation is made for children to help and work with others. For example, during art activities, children are required to make something for a peer rather than for themselves. This may require them to find out information about a peer and then use that information (peer's favorite colors and preferences) to develop a picture for him or her.

Over time due to a combination of social incompetencies and general lack of insight many children with ASD experience rejection by peers. As social encounters become less reinforcing, children with ASD begin to avoid social interactions. Gradually, 
they may develop negative attitudes about themselves and others. Thus poor self-esteem may result making it more difficult to further attempt social interactions and, so, the negative cycle continues. Therefore, another essential ingredient of social skills interventions as put forth by Krasny et al., (2005) is fostering self-awareness, self appreciation, and self-acceptance. To foster self-acceptance, group leaders can regularly comment on members' strengths. Children can be taught the concept of complimenting others and can be expected to compliment their peers.

Social skills difficulties are not simply restricted to children with ASD; many children with other mental health issues such as ADHD can also have difficulty with social skills. Curricula often developed to address general social impairments do not adequately target the social skills deficits specific to ASD (Rao et al., 2008). Thus, when selecting social goals for intervention, it is critical to prioritize and address the skill deficits most specific and relevant to autism. For example, eye contact is probably a greater priority for children with ASD than manners or negotiation skills, given its centrality to social interaction (e.g., to read and interpret social cues and gauge interest or engagement).

To achieve adequate skill mastery and generalization, skills require frequent practice and need to be taught in a sequential manner, building on previous skills. Therefore skills and behaviors addressed across the curriculum should have relevance to each other and build on each other. As more complex, higher-order skills are learned, basic skills learned early must continually be practiced. This practice not only promotes skill maintenance, but also integrates the individual skills into more fluid social 
competence. Complex pro-social skills are broken down into individual components, taught sequentially and finally integrated (Krasny et al., 2005).

White, Keonig and Scahill (2007) conducted a systematic search of published research and unpublished dissertation studies available through August 2006. Based on their review of social skills interventions, they reported many promising intervention strategies such as making social rules clear and concrete, modeling age appropriate initiation strategies, and promoting skill generalization.

\section{Teaching Strategies Employed in this Study}

\section{Social Stories}

Developed by Carol Gray and colleagues (Gray, 1993), social stories are firstperson accounts of ways to increase the child's awareness of problematic social situations. The story contains a description of what is happening, why it might be happening, and how people think and feel about the situation. Social stories should be commensurate with the child's ability and comprehension level and should use less directive terms. Specific guidelines for writing social stories are available (Gray, 1993). Social stories work best when a new skill is being taught and the story is read just before the child has an opportunity to role-play the skill or practice it in a naturalistic environment. An increasing body of literature has shown that social stories are an effective way to teach individuals diagnosed with autism appropriate social behavior and norms (Andrews, 2004; Bader, 2006; Feinberg, 2001).

\section{Role-play}

Role-playing consists of acting out various social interactions that the child would typically encounter such as initiating with another child or maintaining a reciprocal 
interaction. Role-plays give the child opportunities to practice skills in a simulated environment, enabling them to correctly implement these skills in realistic situations. This strategy allows for the child to observe others and become more aware of the importance of learning by observing. When observing others practice a skill appropriately or inappropriately, the child can reflect on what impact the behavior has on the way other people think, feel, and behave. Efforts to improve the generalizability of skills training have shown that targeted, in vivo practice of skills (Glynn et al., 2002), and systematically involving natural supports in helping clients use targeted social skills during their daily interactions (Tauber, Wallace, \& Lecomte, 2000) can maximize treatment gains.

\section{Social scripts}

Children with ASD often lack the knowledge regarding what to do or how to respond in a social situation (an example of a skill deficit) and may respond by saying or doing something inappropriate. Krantz and McClanahan (1993) used scripts to successfully teach children with ASD to initiate asking questions such as, "Would you like some candy or chips?"

\section{Video Self Modeling (VSM)}

VSM is an intervention where children learn skills by observing themselves performing the targeted skill. A videotape is made of the child demonstrating the prosocial skill, and the tape is then played back to the child for review. A strength of VSM is that it allows the child to learn both through observation and through personal experience (much like role playing). Videos, as a visual stimuli, capitalizes on the child's propensity toward visual learning. Charlop-Christy and Daneshvar (2003) used video 
modeling to teach perspective taking to three children with ASD between the ages of 6 and 9. The researchers concluded that the video modeling intervention was a quick and effective procedure for teaching perspective taking and promoting generalization of newly acquired skills.

\section{Nonverbal Activities}

Such activities involve nonverbal problem solving. For example, the correct and incorrect ways of greeting other children can be written on 3 x 5 cards and sorted into two different categories (right way vs. wrong way). Another example is identifying emotions by sorting various emotions based on situations that elicit the emotions (When I go to a birthday party, I feel __. The child chooses the emotion(s) from a written list). Rating scales or thermometers can also be used to quantify emotions to help children understand the continuum of an emotion. For example, an anger thermometer can be used to depict differences between feelings of irritability versus anger (McAfee, 2003).

\section{Group Versus Individual Social Skills Training}

Because children with ASD fail to develop appropriate social skills and often lack opportunities for learning through positive peer interactions, providing explicit training is essential. Group training approaches provide children with opportunities for teaching interactions with other children, which often does not take place explicitly in school settings (Bellini, Peters, Benner, \& Hopf, 2007), and allows for the direct instruction of skills within a structured environment. Group training may utilize resources more effectively by allowing autism specialists, who are often limited in number in outpatient and school settings, to work with many children with ASD simultaneously. Teaching social skills within a group format can enhance and promote skills acquisition, 
maintenance and generalization through interaction with peers and guidance from group leaders. Fun group activities can increase members' motivation to engage and interact with their peers and thus develop friendship skills (Tse et al., 2007). As noted earlier, interest in the effectiveness of group social skills interventions has increased and many examples appear in the literature (e.g., Barnhill, Cook, Tebbenkamp, \& Myles, 2002; Barry et al., 2003; Bauminger, 2007; Crager \& Horvath, 2003; Hwang \& Hughes, 2000; Kroeger, Schultz, \& Newsom, 2007; Lopata, Thomeer, Volker, \& Nida, 2006; Ruble, Willis, \& Crabtree, 2008; \& Tse, Strulovitch, Tagalakis, Meng, \& Fombonne, 2007).

\section{Review of Social Skills Group Research}

Mesibov (1984) was the first investigator to describe and evaluate the effectiveness of a social skills training group for verbal adolescents and adults with ASD. The primary goals of his intervention were to increase interpersonal skills, promote positive peer experiences, and enhance self-esteem. The group met weekly for one hour for two terms of 12 weeks. Techniques included modeling, coaching, and role-playing. Qualitative measures (e.g., participants', families', and staff members' impressions of change) suggested that the program was successful, but objective pre-post testing was not conducted.

Since then, much research has been conducted on the effectiveness of social skills groups. The following are selected studies examining the effectiveness of social skills instruction within a group format using similar teaching methods and targeting social skills and related behaviors, as intended in the current study.

In 1995, Ozonoff and Miller included a comparison group to assess the effectiveness of a social skills intervention. Five adolescent boys participated in a four 
and one-half month training program consisting of modules on interactional, conversational, and perspective-taking skills. Following intervention, improvements on several perspective-taking tasks were noted in the treatment group, as opposed to the notreatment control group. This finding suggests perspective taking abilities improved with intervention and did not automatically do so without it. For this study, the authors reported effect sizes in the medium to large range (effect size for a group difference, treatment vs. control of 1.6) for intervention effects on participants' theory of mind task performance.

Post-treatment ratings completed by participants' parents and teachers, however, suggested that the improvements did not generalize to settings outside the clinic and to real-life measures of social competence. Therefore, teaching problem-solving principles and cognitive mediational strategies did not appear to help participants function socially outside the treatment setting.

Provencal (2003) as part of a doctoral dissertation study investigated the effectiveness of a social skills training program aimed at teaching adolescents with autism spectrum disorders specific social skills and increasing positive peer relationships. Participants in the treatment group $(n=10)$ received social skills training for one and a half hours per week for the duration of 8 months. The comparison group $(n=9)$ received services as usual provided through their school districts and communities. Findings suggested that the treatment positively impacted some autistic symptoms (e.g., improved reciprocal social and communication skills) and self-reported improved socio-emotional functioning (e.g., decreased sense of inadequacy, atypicality, depression, and anxiety). Parent and teacher ratings further suggested improved social skills and decreased acting- 
out behaviors. This study reported large effect symptom reduction $(0.21)$, medium effect on social skills (0.08) and small effect on knowledge of friendship (0.05). Effect sizes were calculated based on the strength of association between the intervention and outcome measure.

Trimarchi (2004), as part of a doctoral research study evaluated a social skills training program for children with Asperger's Syndrome using a control group. In order to add to existing literature on social skills interventions for the ASD population, the researcher implemented a manualized theory-based, short-term group intervention, while giving particular attention to guidelines for demonstrating evidence-based interventions. In addition, the researcher selected and employed multi-method, multi-source measures that provided descriptive, exploratory evidence. Program evaluation was conducted using a multiple case study design. Preliminary evidence suggested that the social skills training program was implemented with integrity and was acceptable to the treatment group children and caregivers. Post-treatment assessment showed no differences in parent/teacher report of symptom severity. Parents reported minimal improvement on targeted social skills; actual effect sizes or significance of improvement were not reported in this study.

Solomon, Goodlin-Jones, and Anders (2004) reported the findings of a 20-week social adjustment enhancement curriculum for boys with ASD aged 8-12. The curriculum was designed to address three areas hypothesized to be deficient in persons with ASD: emotion recognition and understanding; theory of mind; and executive functions/real-life type problem solving. Parents attended a semi-structured concurrent psycho-educational training meeting during childrens' sessions. Statistically significant 
improvements in facial expression recognition $(\mathrm{F}=12.51, \mathrm{P}=.003)$, and problem solving $(\mathrm{F}=4.44, \mathrm{P}<.05)$ were reported for intervention group children compared to waiting list control group children.

Tse, et al., (2007) examined the effectiveness of a social skills training group for adolescents with Asperger syndrome and high-functioning autism (AS/HFA). Parents of six groups of adolescents $(n=46,61 \%$ male, mean age 14.6 ) completed questionnaires immediately before and after the 12-week group of one and a half hours in duration. Significant pre- to post-treatment gains were found on measures of both social competence and problem behaviors associated with AS/HFA. Effect sizes ranged from .34 to .72 . A control or comparison group was not utilized in this study.

Rose and Anketell (2009) conducted a study where 31 children, 6 to 18 years diagnosed with ASD, attended one of four pilot social skills groups. An evaluation of the groups was carried out entailing qualitative data with a parental focus group and quantitative data with pre, post, and review questionnaires. A non-standardized questionnaire was developed to specifically assess the targeted social skills. Parents filled out the questionnaires before the treatment, post treatment and six months after the treatment. From the pre and post questionnaires, parents' reports indicated that the majority of children's difficulties remained the same in terms of mood, social and communication difficulties. The study also showed that a number of parents rated their child as "better" on at least one of these areas, Seven children (37\%) showed improvement or rated "better" in "starting conversations", "reading others' facial expressions/emotions" and "playing/socializing with peers". Improvement was also seen for four children in "continuing conversations", three children in "understanding 
non-verbal communication" and two children in "showing empathy". In contrast, one child was rated as " worse' for three of the areas. Since no formal statistical analysis was completed for this study no effect or P sizes are reported.

Cotugno (2009) examined the effectiveness of a 30 week social competence (one hour/week) and social skills group intervention program with children, ages 7-11 diagnosed with ASD. Eighteen children with ASD were assessed with pretreatment and posttreatment measures on the Walker-McConnell Scale (WMS) and the MGH YouthCare Social Competence Development Scale. Each received the 30-week intervention program. For comparison, a matched sample of 10 non-ASD children was also assessed but received no treatment. The findings indicated that children in the intervention group demonstrated significant gains on the WMS and significant improvement in the areas of anxiety management, joint attention, and flexibility/transitions. P values of treatment gains ranged from .01 to .05 . The control group did not show any significant changes on pre and post measures.

\section{Recommendations from Studies Reviewed}

The present study utilizes the recommendations made by the following review boards and researchers.

The National Research Council (NRC) was given the task of making program recommendations for young children with autism. Social development, including planning for interventions and specific interventions used to teach social skills, is discussed within the committee's comprehensive findings (NRC, 2001). Emphasis was placed on targeting goals for social interactions both with adults and children, providing 
supports for the target child and typical peers, and teaching skills within their natural context and environments,

Rogers (2000) reviewed social interventions with demonstrated empirical support for youth with ASD. Using peer-reviewed journals, Rogers identified interventions that improved social competence. Successful strategies for intervention included peer mediated interventions, adult instruction, and social skill groups. Recommendations were made for further research and study in a number of areas, including measurement and assessment, accessibility to intervention, and the need for additional outcome studies for well-publicized interventions such as social stories and social skills groups.

Commissioned by the Committee on Educational Interventions for Children with Autism of the National Research Council, McConnell (2002) reviewed empirical literature on social interactions and relationships of young children with autism to identify strategies to improve social competence. McConnell summarized recommendations for educational practices as (1) using natural settings throughout the day and activities, (2) targeting interactions with both adults and children, and (3) arranging environments to support interactions, (4) move learners toward naturally occurring contingencies, and (5) systematically monitoring intervention effects.

Bellini, Peters, Penner and Hopf (2007), in their meta-analysis of studies involving 55 single-subject design studies examined the effectiveness of school-based social skills interventions for children and adolescents with ASD. Intervention, maintenance, and generalization effects were measured by computing the percentage of non-overlapping data points. Results from this meta analysis suggested that school-based social skills interventions were minimally effective for children with ASD. He also found 
statistically significant differences between interventions implemented in the child's typical classroom and studies implemented in pullout settings. That is, studies implemented in the child's typical classroom setting produced significantly higher intervention maintenance and generalization effects than interventions that involved removing the child from the classroom.

Gresham, Sugai and Horner (2001) based on their analysis of narrative and quantitative social skills training (SST) literature concluded that SST can produce both small and large effects on social competence functioning. From a meta-analytic perspective, they found rather large differences in overall effect sizes ranging from .20 to .87. The authors attributed these differences to characteristics such as (a) Population characteristics: meaning overall severity of the problem in the population and related intervention dosage levels. Optimal ages for intervention could also be a critical factor. (b) Matching treatments to type of social skills deficit: SST interventions for acquisition deficits are different from interventions for performance deficits and fluency deficits. Procedures for acquisition deficits assume that the individual does not possess the social skill and is missing a step in performing a social skill sequence. Specific interventions to address these deficits would include modeling, coaching, behavior rehearsal, and performance feedback in a small group setting. Interventions for enhancing performance of previously acquired skills, on the other hand, would take place in naturalistic settings using manipulation of antecedents such as peer tutoring, incidental teaching, or manipulation of consequences including differential reinforcement, etc. (c) Treatment integrity issues: is concerned with the accuracy and consistency with which treatments are implemented. (d) Assessment issues: weak effects of SST can be the use of 
assessments that show little correspondence between the behaviors that are assessed and those behaviors that are taught and (e) Generalization issues: involves the failure to demonstrate sufficient generalization and maintenance of instructed skills.

Koenig, Reyes, Cicchetti, Scahill, and Klin (2009) in their evaluation of SSTs conclude that outcome data are inconclusive. They ascribed challenges to research of SST with the ASD population to the complex constructs being targeted and assessed such as "social reciprocity" and impaired social functioning. They argue that these complex constructs require a multi-dimensional, multi-method approach to intervention and measurement of gains. The impairment is further complicated by multiple factors, including the child's level of cognitive functioning, the presence of behavioral rigidity, the presence of anxiety or other co-morbid conditions, the degree of receptive and expressive language impairment, and the degree and severity of stereotypic or repetitive behaviors (Volkmar, Paul, Klin \& Cohen, 2005). They recommended choosing a specific aspect of the construct for intervention and then specifying the skills within that construct to address. They also recommended the careful choice of multiple informants, attending to the need for varying perspectives and contexts through which observations of target behaviors are made.

\section{Assessment Measures}

There are several methods available to assess social skills, such as standardized approaches and criterion-based methods. Standardized pre and post measures allow for detection of treatment effectiveness. One example of standardized measures of social skills is the Social Skills Rating System (SSRS: Gresham \& Elliott, 1990), which is a commonly used measure of actual skill use. Other measures are the Social 
Responsiveness Scale (Constantino, Przybeck, Friesen \& Todd, 2000) and the Social Competence Inventory (Rydell, Hagekull, \& Bohlin, 1997). Although standardized measures are helpful in comparing the child's skills to norm-referenced groups, they are often insufficient for determining specific social skills objectives for an individual child or measuring progress as a result of intervention (Murray, Ruble, Willis, \& Malloy, 2007).

Criterion-based assessments, in contrast to norm-referenced measures, often are more specific to the targeted skills and actual intervention being implemented. Criterionbased measures are often an important ingredient in measuring the overall effectiveness of a social skills intervention (Ruble, Willis, \& Crabtree, 2008).

\section{Conclusion}

In summary social skills deficits are a defining feature of ASD and if left untreated will persist impacting all aspects of life. Group training approaches tend to provide children with opportunities for teaching interactions with other children which often do not take place explicitly in other settings. Social skills interventions for individuals with ASD need to take into account the specific learning differences of individuals with ASD. Outcome research for social skills training so far tends to be mixed and inconclusive. While improvements have been noted on specific discrete social skills, a major criticism has been the lack of generalizability of improvements outside the treatment setting. This factor has been addressed as the research to practice gap, where effectiveness of interventions are difficult to replicate across all contexts. Another major handicap has been the complexity or abstract nature of the topic under study and precision of measurement of the targeted behavior. 
The current research takes into consideration the recommendations made by the reviewers above in terms of understanding the complexity of the construct being studied and utilizing both standardized and criterion-based measurements to track effectiveness. Further, the interventions are tailored to the specific skill deficits prevalent in individuals with ASD, and the study is designed to incorporate generalization and maintenance of skills through environmental adaptations and parent training, as previously described in both the camp and clinic model. The intervention takes into consideration the learning differences of children on the spectrum and targets the skill deficits associated with this population. The intervention is thus designed to be comprehensive as described by McConnell in 2002, customized to address the needs of the affected child, while maintaining treatment integrity. 


\section{CHAPTER III}

\section{METHODS}

The purpose of this study is to evaluate the effectiveness of a comprehensive Social skills curriculum developed for children with ASD and adapted to two different contexts, the camp and clinic models. The camp model simulates a natural setting where children with ASD spend five hours each day for 10 days where social skills are taught and reinforced by clinicians and paraprofessionals through engaging activities and interactions with peers both typical and with ASD. The clinic model, on the other hand, is a more traditional one hour a week session spread over 10 to 12 weeks where social skills are taught and practiced while parents observe through a one-way mirror and are trained on the intervention methods. Both clinic and camp model treatments are then compared with a third group who experience both treatments within the clinic and camp setting.

\section{Social Skills Curriculum and Teaching Strategies}

Topics chosen for instruction are based on skill deficits commonly identified from parental report from the pre assessment, the Triad Social Skills Assessment (TSSA) developed by Stone, et al., in 2002 . Table 1 outlines an overview of a typical 10-week instructional format. A combination of psycho- educational and behavioral methods of teaching social skills, with an emphasis on learning with the strategies identified in Table 1 , is applied. 
Table 1

Example of 10-day Social Skills Instruction Program

\begin{tabular}{lll}
\hline Week & Topic & Instructional Methods \\
\hline 1 & Introductions \& & Visual supports; social stories; social scripts; role \\
& Initiating: Greetings & play; nonverbal activities \\
\hline 2 & Initiating: Friends and & Visual supports; social stories; social scripts; role \\
& strangers & play; nonverbal activities \\
\hline 3 & Initiating: Complimenting & Social stories; nonverbal activities (identifying \\
& others & steps to problem solving, generating solutions); \\
& & modeling, role-play \\
\hline 4 & Problem Solving & Social story; nonverbal activities; role-plays \\
\hline 5 & Being a good sport & Social story; role-plays (setting up scenarios such \\
& & as board or other games to provide opportunities to \\
& & demonstrate cooperative play) \\
\hline 6 & Emotion regulation & Visual supports; sorting activities; nonverbal \\
& & activities (feelings thermometer, calming \\
& & strategies) role-plays \\
\hline 7 & Use and understanding of & Visual supports; video self modeling; role play \\
& body language and & \\
\hline & showing Listening & activities \\
& & \\
\hline & & Social story; social scripts; role-play (different \\
& & \\
& &
\end{tabular}




\begin{tabular}{lll}
\hline 9 & Conversational skills: & Visual supports; video self modeling; role play \\
& maintaining conversations & \\
& and staying on topic & \\
\hline 10 & Conversational skills: & Visual supports; role-play; video self modeling \\
& Terminating conversations & \\
\hline
\end{tabular}

The 10 sessions can be classified under three major targeted skills: (a) initiating skills (first three sessions); (b) understanding emotions, perspective taking, and problem solving (4 sessions); and (c) conversational skills (sessions 8-10). Resources for the above curriculum were primarily adapted from four sources: (a) Social Skills Training (Baker, 2003); (b) Super Skills (Coucouvanis, 2005); (c) Talkabout (Kelly, 1996); and (d) Skills Training for Children with Behavior Problems (Bloomquist, 2006).

Within the context of a comprehensive program, several instructional components were used and include the use of visual supports, role-playing, social stories, social scripts, video self modeling and rehearsal, and nonverbal problem- solving activities (Baker, 2003; Coucouvanis, 2005; Buggey, 1999; White et al., 2007). All instruction included modeling, rehearsal, and feedback and generally consisted of four steps; (a) introducing the topic with a social story, (b) explaining through nonverbal activities and modeling the correct behavior, (c) conducting role-plays through simulated situations of the skills, and (d) disseminating homework to practice the skill.

Visual supports ranged from use of schedules that help children understand the order of events within the group to pictures that illustrate abstract social norms. Social Stories were written commensurate with the child's ability and comprehension level for 
the primary purpose of increasing the child's awareness of problematic social situations. Role-plays gave the child opportunities to practice skills in a simulated environment, thus enabling them to correctly implement these skills in realistic situations. Social scripts were used in situations when children did not know how to initiate or respond in situations. Video self modeling was used when applicable where it was determined by the clinician responsible that a particular group of children could benefit from it.

\section{Treatment Fidelity}

Once the curriculum was developed, all clinicians participating and or assisting at camp or clinic sites were trained by the investigator. All clinicians utilized have prior experience in working with children with ASD and were employees with the autism treatment component of the University of Louisville Autism Center. The training involved ensuring that other clinicians were well versed with the manual and cold operate the entire 10 to 12 week curriculum within the clinic context under the supervision of the author of the manual. While teaching strategies and skill concepts remained consistent from group to group, adaptations were made for individual children when necessary with regard to level of language used in social narratives and range of visuals required for teaching abstract concepts. The same clinicians were responsible for all clinic and camp participants. Clinicians met at the end of each group, both clinic and camp, to discuss core treatment concepts to be covered and checked.

\section{Sample}

Twelve children between the ages of 8 to 14 with an ASD diagnosis of Autism, Aspergers, or Pervasive developmental Disorder, Not Otherwise Specified (NOS) received from a psychologist or physician and referred to the clinic for social skills 
training were selected from each of the 3 treatment modalities: camp alone, clinic alone, and those who had attended both camp and clinic treatments. Before participating in the social skills groups, the children completed a manualized social skills assessment for individuals with ASD (Stone, Ruble, Coonrod, Hepburn, \& Pennington, 2002) to ensure that they had appropriate task demand skills such as abilities to understand verbal instructions, conduct role-plays, answer questions, read simple questions, and speak in complete sentences spontaneously. This was a clinical sample, not recruited for research. Formal tests of intelligence and language were not performed. The current study was approved by the University of Louisville Institutional Review Board. The study comprised 12 children each in the camp only and clinic only model and 13 children who had received both treatments. Table 2 describes the composition and group characteristics of the three treatment groups. 
Table 2

Sample Characteristics of the 3 Groups

\begin{tabular}{lllllll}
\hline Group & Average & Number of & $\begin{array}{l}\text { Number of } \\
\text { females }\end{array}$ & $\begin{array}{l}\text { Autism } \\
\text { Diagnosis }\end{array}$ & $\begin{array}{l}\text { Aspergers } \\
\text { Diagnosis }\end{array}$ & $\begin{array}{l}\text { NDD- } \\
\end{array}$ \\
& Age & males & & & & \\
& & & & & & Diagnosis \\
\hline Clinic & 12 years 2 & 9 & 3 & 6 & 6 & 0 \\
only & months & & & & & \\
\hline Camp & 12 years 5 & 11 & 1 & 6 & 4 & 2 \\
only & months & & & & & \\
\hline Camp and & 12 years 4 & 8 & 5 & 7 & 6 & 0 \\
Clinic & months & & & & & \\
\hline
\end{tabular}

\section{Camp Structure}

Approximately 25 children with an ASD diagnosis attend camp each summer for two weeks hosted by the treatment component of the Autism Center at the University of Louisville. Children are typically divided into five groups based on age and language ability. A minimum of two typical peers are assigned to each group. The typical peers are trained to initiate and interact with children with ASD by clinicians prior to the start of camp. Campers begin at 9.00 am each morning. After an hour of small group social skills instruction, they move on to a series of fun, interactive activities with their peers. An outline of the camp schedule is detailed in Table 3. 
Table 3

\section{Camp Schedule}

\begin{tabular}{ll}
\hline Time & Activity \\
\hline 9.00 to $9.30 \mathrm{am}$ & Chores for the day \\
\hline 9.30 to $10.30 \mathrm{am}$ & Social skills group \\
\hline 10.30 to $11.00 \mathrm{am}$ & Board games \\
\hline 11 to $11.30 \mathrm{am}$ & Gym activities \\
\hline 11.30 to $12.00 \mathrm{pm}$ & Lunch \\
\hline 12 to $12.30 \mathrm{pm}$ & Out door games \\
\hline 12.30 to $1.00 \mathrm{pm}$ & Craft time \\
\hline 1.00 to $2.00 \mathrm{pm}$ & Large group activity (magic show, fun with \\
& inflatables, etc.) \\
\hline
\end{tabular}

After the skill of the day is taught in the social skills group, participants are encouraged to practice these skills through the different activities with their peers using a reward system. For example, if the skill taught involved how to initiate through complimenting others, the skill is practiced and reinforced through other activities that follow, such as complementing fellow campers on their craft, on their sportsmanship, etc. When children are caught demonstrating the skill of the day with other campers, they are rewarded through praise and earn tokens to earn a tangible reinforcer. At the end of the day, therapist briefly meets with parents to discuss the skill taught and to disseminate home work to practice at home and in other environments. Children in the camp modality attend 10 consecutive days (except week-ends) for a total duration of five hours each per day. Total time spent at camp is 50 hours within 2 weeks. 


\section{Clinic Format}

In the clinic modality, children attend small group sessions where the skills described in Table 1 are taught. The duration of each session is about an hour and incorporates the teaching methods described in Table 1. At the start of each session, parents are briefly met by a clinician who describes the skill of the day and the teaching methods involved. The sessions are then observed by parents through a one way mirror facilitating parent training in skill instruction and, thereby, generalization to other environments. Parents meet with the same clinician at the end of the session to ask questions and receive the support materials utilized in the session, such as social stories, visuals, and other supports. Homework is given to each child to practice the skill they learnt in the session in other environments. The homework is shared and reviewed with the parent at each session. Parents are encouraged to share the material with teachers at school. Sessions are conducted weekly and continue for up to 10 or 12 weeks. Total treatment time is 10 or 12 hours depending on the needs of the group.

\section{Combined Model}

Children in this group received the camp and clinic treatments for a total of $60 / 62$ hours. The treatments did not follow any particular sequence, it could have been camp followed by clinic treatment or vice versa. A child in the combined model could have participated in the clinic treatment in the spring and attended camp in the summer, or attended camp in the summer and the clinic treatment in the fall of the same year. 


\section{Instrumentation}

The dependent measures used in this study were the Social Responsiveness Scale (SRS: Constantino, Przybeck, Friesen, \&Todd, 2000); the TRIAD Social Skills Assessment (TSSA: Stone, Ruble, Coonrod, Hepburn, \& Pennington, 2002); the Aberrant Behavior Checklist (ABC: Aman, Singh, Stewart \& Field, 1985); and a Therapist Rating Scale (TRS). Parents of children in the treatment and comparison groups completed the SRS, the TSSA and the ABC before and after the treatments. Therapists involved in the treatment groups completed their ratings of children's social skills pre and post treatment. SRS

The SRS is a 65-item informant-based measure of children's (4-18 years) social competence, where social deficits are represented as quantitative traits rated on a 4-point Likert scale (Constantino, Przybeck, Friesen, \& Todd, 2000). There are five treatment subscales: "Social Awareness"' (8 items), "Social Cognition" (12 items), "Social Communication" (22 items), "Social Motivation" (11 items) and “Autistic Mannerisms" (12 items) All are sensitive to change in social deficits. Three "DSMoriented" subscales measured "Social Aspects" (47 items), "Language Aspects" (6 items) and "Preoccupations and Mannerisms" (12 items) of autism, as described in DSM-IV. The SRS was designed for completion by a parent, teacher, or other primary caregiver who knows the child well. Completion time is about 15 to 20 minutes. The instrument provides an overall picture of a child's social behavior as it occurs in natural social settings and is useful as a research instrument and intervention tool for measuring 
the progress of children in response to intervention. The descriptions of subscales are as follows.

1. Social Awareness: The ability to pick up on social cues. Items represent the sensory aspects of reciprocal social behavior.

2. Social Cognition: The ability to interpret social cues after they are recognized. Items represent the cognitive-interpretive aspects of reciprocal social behavior.

3. Social Communication: Includes expressive social communication. Items represent the motoric aspects of reciprocal social behavior.

4. Social Motivation: The extent to which the individual is generally motivated to engage in social-interpersonal behavior. Items include elements of social anxiety, inhibition, and empathic orientation.

5. Autistic Mannerisms: Includes stereotypical behaviors or highly restricted interests that are characteristic of autism.

Raw scores for the total test and the subscales were converted into T-scores. Total T-scores of 76 and higher fall into the severe range and suggest the presence of an autism spectrum condition. T-scores of between 60 and 75 are in the moderate range and may suggest the presence of mild autism spectrum disorders such as PDD-NOS or Asperger's Disorder. Scores of 59 or less are in the normal range and suggest the absence of an autism spectrum condition.

The SRS exhibits strong correlations with DSM-IV criterion scores generated from the ADI-R (Constantino et al., 2008) and distinguishes patients with pervasive developmental disorders (PDDs) from children with other child psychiatric conditions (Constantino et al., 2000). Scores on the SRS are highly heritable, generally unrelated to 
IQ, and continuously distributed in the general population (Constantino \& Todd, 2000; Constantino et al., 2003; Constantino \& Todd, 2003). Internal consistency, interrater reliability, and test retest reliability are all well within the acceptable range for behavioral assessments (Constantino \& Gruber 2005).

TSSA

The TSSA is a criterion-based assessment and is more specific to the skills that are being addressed within the intervention. The TSSA was developed specifically for children with ASD who are verbal and able to communicate in sentences (Stone et al., 2002). The parent and teacher forms evaluate problem behaviors that interfere with friendships; the child's understanding of emotions and perspectives of others; and skills reflecting initiating, maintaining, and responding to others. Criterion-related assessment of social skills helps target specific individual as well as group behavior objectives. Further, the assessment includes Likert-type scales for which therapists can rate perceived changes in the child's social behavior over the course of a group or individual sessions. The TSSA consisted of five subscales: Problem behaviors, affective understanding/perspective taking, initiating interactions, responding to initiations, and maintaining interactions. Parents rate their children for social skills behaviors on a 4point Likert scale ranging from 1 ( not very well) to 4 (very well). Total scores are obtained by summing individual ratings for each subscale. Problem behaviors are also rated on a 4-point Likert scale ranging from 1 (not at all problematic) to 4 (very problematic). A total score for problem behaviors is obtained by summing individual ratings. A higher score in this category would indicate more problem behaviors. The TSSA is not norm-referenced and does not have reliability or validity statisics. 


\begin{abstract}
$\mathbf{A B C}$
Tools that help with assessment of generalization may evaluate collateral skills such as problem behaviors that occur as a result of social or communication deficits. Hence pre and post measures of problem behaviors can help determine treatment effectiveness. The $\mathrm{ABC}$ is a 58 -item informant-based measure of problem behaviors of individuals with developmental disabilities, rated on a 4-point Likert scale (Aman, Singh, Stewart, \& Field, 1985). There are five subscales: "Irritability"' (15 items); "Lethargy, Social Withdrawal"'(16 items); "Stereotypic Behavior"' (7 items); "Hyperactivity"' (16 items); and "Inappropriate Speech" (4 items). Specifically, the ABC is designed to evaluate treatment effects of individuals with problem behavior. An informant rates the behavior described in the item on a Likert scale of 0 to 3 , with " 0 " indicating not at all a problem and "3" indicating the problem is severe in degree. The manual does not specify the length of time the rater should be familiar with the subject prior to completion of the instrument, but rather it is suggested that he or she have a "knowledge" of a subject's behavior in a variety of settings. The authors provide excellent operational definitions for each item. With familiarity, the rater should be able to complete the $A B C$ within five minutes. Scoring is also easily accomplished. The authors indicate that the scale was empirically derived via factor analyses, which yielded the following five subscales: Irritability, Lethargy, Stereotypy, Hyperactivity, and Inappropriate Speech. Scores were derived by summing the items that comprise each scale. The subscale raw scores may then be compared to the average scores of subjects stratified by gender, age, and national
\end{abstract}


origin (New Zealand vs. United States). Alpha coefficients ranged from 0.77 to 0.95

across subscales (Brown, Aman, \& Havercamp, 2002).

\section{Therapist Rating Scale (TRS)}

Is a condensed version of the social skills subscales of the TSSA developed to assist therapists in rating progress of children who attend the social skills groups. The therapist rates each child on a 3-point Likert scale ranging from 1 (never/seldom) to 3 (very often). Three subscales assess for initiating, maintaining interactions and responding to others. Therapists completed pre-and post-evaluations of each child in all 3 treatment modalities.

Thus various aspects of social skills were assessed by the SRS, four scales of the TSSA (TSSA2 through TSSA5), and the TRS. Associated behaviors were assessed by the $\mathrm{ABC}$ and the first subscale of the TSSA (TSSA1). Multiple methods were used to measure change in social skills and related behaviors as recommended in social skills group intervention (Koenig, De Los Reyes, Cicchetti, Scahill, \& Klin, 2009). Multiple measures are recommended as the focus of intervention is multidimensional and complex, requiring comprehensive evaluation.

\section{Method}

$A$ fter obtaining IRB approval pre-and post-measures of 12 subjects from each treatment modality with ASD between the ages of 8 to 14 were collected from their medical records. The total number of participants amounted to 37 . There were 12 subjects each in the camp only and clinic only models and 13 in the combined model. This data was then compiled in the Statistical Package for the Social Sciences (SPSS version 17) database, which was then used to perform subsequent analysis. 


\section{Hypotheses}

1. There will be no difference in pre and post scores on the measures used to test the efficacy of the socials skills treatment and collateral behaviors in the clinic condition.

2. There will be no difference in pre and post scores on the measures used to test the efficacy of the socials skills treatment and collateral behaviors in the camp condition.

3. There will be no difference in pre and post scores on the measures used to test the efficacy of the socials skills treatment and collateral behaviors in the camp and clinic condition.

4. There will be no difference in pre and post scores as a result of treatment condition.

\section{Statistical Analysis}

For the testing of hypotheses 1 through 3 , average gains or differences on measures of behavior and social skills within each group were analyzed using paired ttests for the pre versus post comparison within each treatment group. To control for type 1 error due to multiple comparisons, raw p values will be adjusted using the Benjamin and Hochberg (BH) False Discovery Rate (FDR) procedure. BH multiple comparison adjustments will be based on all 18 subscales of the 4 measures used within each treatment group. The $\mathrm{BH}$ procedure is found to be most optimal under dependence as it achieves relatively high power while remaining conservative (Kim \& Van de Weil, 2008). Effect sizes were calculated using Cohen's $d$ for each pre and post data pair to 
substantiate the magnitude of treatment effect, control for type 2 errors, and facilitate comparison of this study with similar studies. Effect size values for $\mathrm{d}$ are considered small at 0.2 , medium at 0.5 , and large at 0.8 .

For comparison between the three groups, an ANCOVA (Analysis of Covariance Model) was conducted on each dependent variable, with post scores as the dependable variable, pre scores as the covariate and treatment modality or group as the fixed factor. ANCOVA was selected over repeated measures ANOVA (Analysis of Variance) on change scores to reduce error variance and to adjust the means on the covariate so that the mean covariate score is the same for all groups. This procedure eliminates any subject variances across the three treatment groups (Dugard \& Todman, 1995). 


\section{CHAPTER IV}

\section{RESULTS}

This study investigated the use of a social skills curriculum designed to improve social skills and collateral behaviors across three different settings: the clinic setting, the camp setting, and a combined model incorporating both clinic and camp settings. The findings are organized into four main sections: (a) analysis of pre and post data in the clinic only setting, (b) analysis of pre and post data in the camp only setting, (c) analysis of pre and post data in the combined setting, and (d) analysis of pre and post data across the three groups.

In all three settings, pre and post data was analyzed on four measures assessing for collateral behaviors and social skills. The ABC and TSSA1 were used for the assessment of collateral behaviors. The SRS, four subscales of the TSSA and the TRS were used for the assessment of social skills. A total of 18 dependent variables were analyzed under each treatment modality and across the three different treatment settings.

\section{Clinic Setting}

A paired-samples t-test was conducted to compare the pre and post scores on the 18 variables of the four measures in the clinic condition. 
Pre and Post Analysis of Problem Behaviors

Table 4

Paired Sample Statistics of Behavior Scores in the Clinic Condition

\begin{tabular}{|c|c|c|c|c|c|c|}
\hline & & Mean & $\begin{array}{c}\text { Std. } \\
\text { Deviation }\end{array}$ & $\begin{array}{l}\text { Raw p } \\
\text { values }\end{array}$ & $\begin{array}{l}\text { Adjusted } \\
\text { BH p values }\end{array}$ & $\begin{array}{l}\text { Effect } \\
\text { size (d) }\end{array}$ \\
\hline \multirow{2}{*}{$\begin{array}{l}\text { Pair } 1 \\
\text { Irritability }\end{array}$} & $A B C$ pretest & 7.8333 & 5.65418 & 0.12 & 0.23 & 0.27 \\
\hline & $A B C$ posttest & 6.3333 & 5.28004 & & & \\
\hline \multirow{2}{*}{$\begin{array}{l}\text { Pair } 2 \\
\text { Lethargy }\end{array}$} & $A B C$ pretest & 12.2500 & 8.34620 & 0.18 & 0.23 & 0.16 \\
\hline & $A B C$ posttest & 11.0000 & 6.87552 & & & \\
\hline \multirow{2}{*}{$\begin{array}{l}\text { Pair } 3 \\
\text { Stereotypy }\end{array}$} & $A B C$ pretest & 4.5000 & 4.12311 & 0.14 & 0.23 & 0.33 \\
\hline & ABC posttest & 3.2500 & 3.44106 & & & \\
\hline \multirow{2}{*}{$\begin{array}{l}\text { Pair } 4 \\
\text { Hyperactivity }\end{array}$} & $A B C$ pretest & 12.2500 & 5.37883 & 0.03 & 0.13 & 0.48 \\
\hline & $A B C$ posttest & 9.7500 & 4.82654 & & & \\
\hline \multirow{2}{*}{$\begin{array}{l}\text { Pair } 5 \\
\text { Inappropriate }\end{array}$} & $\mathrm{ABC}$ pretest & 3.2500 & 2.95804 & 0.08 & 0.19 & 0.59 \\
\hline & ABC posttest & \multicolumn{5}{|c|}{ speech } \\
\hline Problem & TSSA pretest & 55.6667 & 12.30915 & 0.18 & 0.23 & 0.46 \\
\hline behaviors & TSSA posttest & 50.4167 & 10.84987 & & & \\
\hline
\end{tabular}

In reviewing table 4 , of the 6 pre to post treatment differences, none were statistically significant on the adjusted $\mathrm{BH} p$ values, while trends to significance are observed on the raw $p$ values. Effect sizes ranged from 0.16 to 0.59 for improvement of collateral behaviors in the clinic only condition. 
These results indicate that statistical significance was not attained on the adjusted $p$ values. Small to moderate effect sizes are noted on improvement of collateral behaviors.

\section{Pre and Post analysis of Social skills}

As assessed by the SRS.

As indicated in Table 5, none of the five pre to post differences were statistically significant at the 0.05 level. Effect sizes ranging from 0.05 to 0.50 were obtained on social skills as assessed by the SRS in the clinic only condition.

These results indicate that modified $\mathrm{p}$ values did not show significant gains on the SRS for this group. Small to moderate treatment gains are noted on this measure. 
Table 5

Paired Sample Statistics of SRS Scores in the Clinic Condition

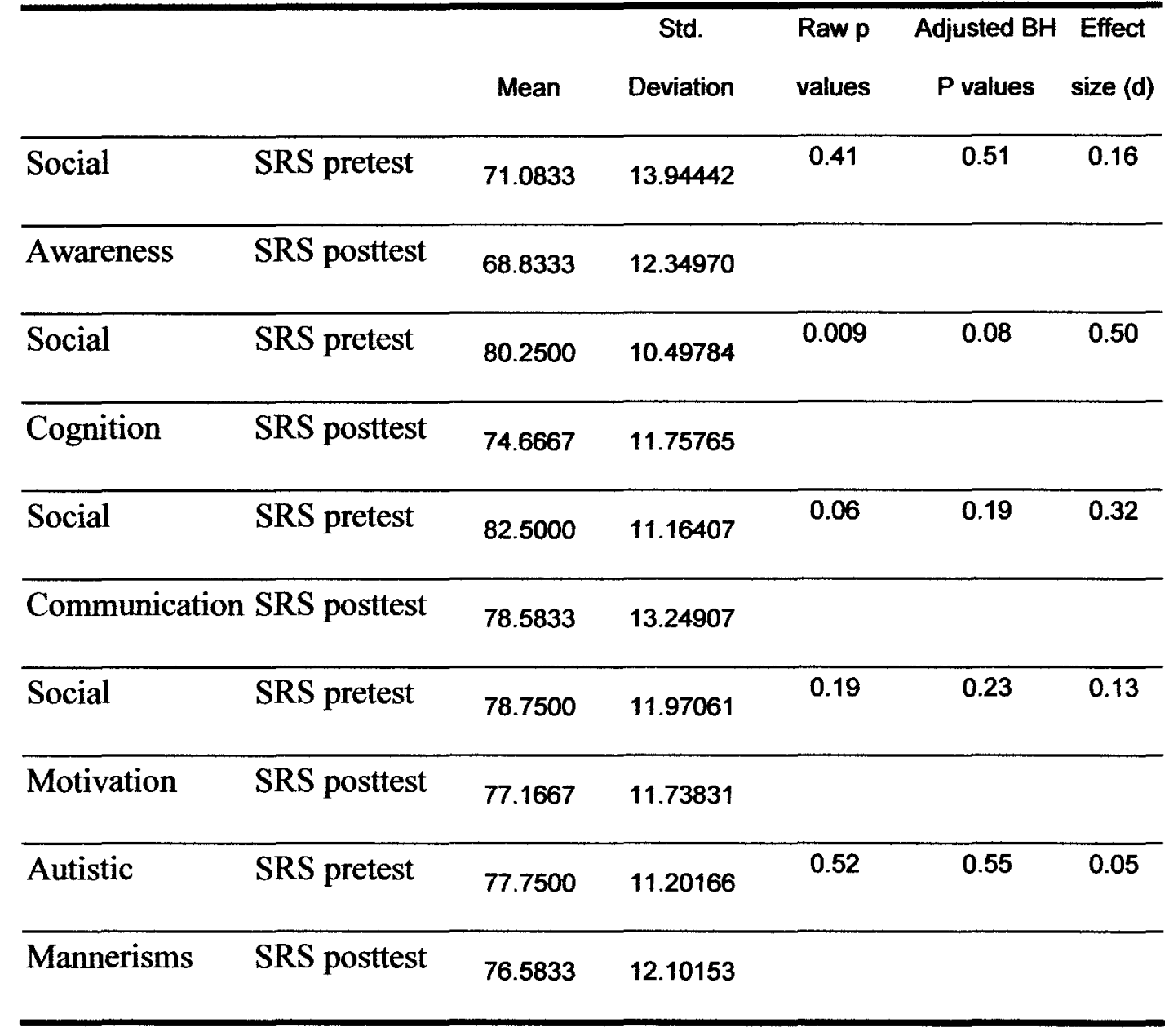

As assessed by the TSSA

A close observation of Table 6 indicates that parent ratings of post TSSA

subscales show no significant improvement on all four of the social skills subscales.

Effect sizes range from 0 to 0.79 for treatment of social skills, as assessed by the TSSA in the clinic only condition. 
Table 6

Paired Sample Statistics of TSSA Scores in the Clinic Condition

\begin{tabular}{|c|c|c|c|c|c|c|}
\hline & & Mean & $\begin{array}{c}\text { Std. } \\
\text { Deviation }\end{array}$ & $\begin{array}{l}\text { Raw } p \\
\text { values }\end{array}$ & $\begin{array}{c}\text { Adjusted BH } \\
\text { P values }\end{array}$ & $\begin{array}{l}\text { Effect } \\
\text { size (d) }\end{array}$ \\
\hline $\begin{array}{l}\text { Affective } \\
\text { understanding }\end{array}$ & TSSA pretest & 16.1667 & 3.85730 & 1.00 & 1.00 & 0 \\
\hline $\begin{array}{l}\text { Perspective } \\
\text { taking }\end{array}$ & TSSA posttest & 16.1667 & 4.83986 & & & \\
\hline Initiating & TSSA pretest & 19.7500 & 6.85068 & 0.16 & 0.23 & 0.36 \\
\hline interactions & TSSA posttest & 22.0833 & 5.85364 & & & \\
\hline Responding to & TSSA pretest & 11.6667 & 3.42008 & 0.15 & 0.23 & 0.44 \\
\hline initiations & TSSA posttest & 13.2500 & 4.07040 & & & \\
\hline Maintaining & TSSA pretest & 25.6667 & 5.94418 & 0.004 & 0.08 & 0.79 \\
\hline interactions & TSSA posttest & 30.8333 & 7.04316 & & & \\
\hline
\end{tabular}

The above results indicate that the treatment did not have a significant improvement on the TSSA subscales in the clinic only condition. Zero to large effect sizes are observed in treatment gains on the TSSA. 
As assessed by the TRS.

Table 7

Paired Sample Statistics of TRS Scores in the Clinic Condition

\begin{tabular}{|c|c|c|c|c|c|c|}
\hline & & Mean & $\begin{array}{c}\text { Std. } \\
\text { Deviation }\end{array}$ & $\begin{array}{l}\text { Raw p } \\
\text { values }\end{array}$ & $\begin{array}{c}\text { Adjusted BH } \\
\text { P values }\end{array}$ & $\begin{array}{c}\text { Effect size } \\
\text { (d) }\end{array}$ \\
\hline Initiating & TR pretest & 5.3333 & 2.60536 & 0.03 & 0.13 & 0.54 \\
\hline interactions & TR posttest & 6.6667 & 2.60536 & & & \\
\hline Maintaining & TR pretest & 6.3333 & 3.17185 & 0.08 & 0.19 & 0.34 \\
\hline interactions & TR posttest & 7.3333 & 2.87096 & & & \\
\hline Responding to & TR pretest & 7.1667 & 2.62274 & 0.02 & 0.12 & 0.62 \\
\hline others & TR posttest & 8.6667 & 2.30940 & & & \\
\hline
\end{tabular}

Analyses of mean scores of therapist ratings (Table 7) show that therapist ratings were not significant at the 0.05 level on the modified $p$ values. Effect sizes range from 0.34 to 0.62 on this measure of improvement observed by clinicians involved in the clinic only condition.

The above results indicate that therapists' observations of social skills on all three of the subscales, as assessed by the TRS in the clinic only condition, were not significant. Small to moderate effect sizes are noted in treatment gains on the TRS in this condition.

In summary, none of the adjusted $p$ values of the 18 variables measuring social skills and related behaviors were significant at the 0.05 level. Effect sizes range from 0.16 to 0.59 on improvement of negative and problem behaviors, as assessed by the $\mathrm{ABC}$ 
and TSSA1. Effect sizes range from 0 to 0.79 on improvement of social skills as assessed by the SRS, TSSA, and TRS.

\section{Camp Setting}

A paired-samples t-test was conducted to compare the pre and post scores on the 18 variables of the four measures in the camp condition.

\section{Pre and Post analysis of problem behaviors:}

In Table 8, a decrease in mean post scores is seen on all 5 subscales of the $\mathrm{ABC}$ and TSSA1 indicating lower incidence of parent reporting of problem and negative behaviors such as irritability, lethargy, stereotypy, hyperactivity and inappropriate speech. Of the 6 pre to post test differences, three (irritability, hyperactivity, and problem behaviors) were significant at the 0.05 level. Effect sizes range from 0.11 to 0.48 for improvement of behaviors in the camp only condition.

These results indicate that the treatment had a significant effect on problem behaviors, irritability, and hyperactivity in children in this group. Effect sizes range from minimal to moderate in treatment gains of behaviors in this condition. 
Table 8

Paired Sample Statistics of ABC Scores in the Camp Condition

\begin{tabular}{|c|c|c|c|c|c|c|}
\hline & & Mean & $\begin{array}{c}\text { Std. } \\
\text { Deviation }\end{array}$ & $\begin{array}{l}\text { Raw p } \\
\text { values }\end{array}$ & $\begin{array}{c}\text { Adjusted BH } \\
\text { P values }\end{array}$ & $\begin{array}{c}\text { Effect size } \\
\text { (d) }\end{array}$ \\
\hline \multirow[t]{2}{*}{ Irritability } & ABC pretest & 13.5000 & 7.41620 & 0.01 & 0.05 & 0.47 \\
\hline & ABC posttest & 10.4167 & 5.59965 & & & \\
\hline \multirow[t]{2}{*}{ Lethargy } & $A B C$ pretest & 10.7500 & 7.94441 & 0.44 & 0.46 & 0.13 \\
\hline & ABC posttest & 9.8333 & 6.07279 & & & \\
\hline \multirow[t]{2}{*}{ Stereotypy } & ABC pretest & 6.1667 & 5.52405 & 0.25 & 0.30 & 0.11 \\
\hline & ABC posttest & 5.5833 & 5.03548 & & & \\
\hline \multirow[t]{2}{*}{ Hyperactivity } & $A B C$ pretest & 17.8333 & 10.87811 & 0.006 & 0.04 & 0.36 \\
\hline & ABC posttest & 14.3333 & 8.63748 & & & \\
\hline \multirow{2}{*}{$\begin{array}{l}\text { Inappropriate } \\
\text { Speech }\end{array}$} & $A B C$ pretest & 4.6667 & 3.82179 & 0.08 & 0.12 & 0.18 \\
\hline & ABC posttest & 4.0000 & 3.49025 & & & \\
\hline Problem & TSSA pretest & 64.6667 & 11.56274 & 0.02 & 0.05 & 0.48 \\
\hline behaviors & TSSA posttest & 58.7500 & 12.66437 & & & \\
\hline
\end{tabular}

As assessed by the SRS.

From table 9, none of the 5 pre to post test differences, were significant at the 0.05 level. Effect sizes ranged from 0.11 to 0.54 for improvement of social skills as assessed by the SRS in the camp only condition.

These results indicate that none of the adjusted $\mathrm{p}$ values were statistically significant at the 0.05 level. Effect sizes indicate minimal to moderate treatment gains in this condition 
Pre and Post Analysis of Social Skills

Table 9

Paired Sample Statistics of SRS Scores in the Camp Condition

\begin{tabular}{lcccccc}
\hline & & & Std. & Raw p & Adjusted BH Effect size \\
& & Mean & Deviation & values & P values & (d) \\
\hline Social & SRSpre1 & 67.8333 & 9.74057 & 0.08 & 0.12 & 0.36 \\
\hline Awareness & SRSpos1 & 64.5000 & 8.26273 & & & \\
\hline Social & SRSpre2 & 77.3333 & 12.78019 & 0.46 & 0.46 & 0.11 \\
\hline Cognition & SRSpos2 & 75.9167 & 12.58035 & & & \\
\hline Social & SRSpre3 & 77.7500 & 10.63549 & 0.32 & 0.36 & 0.26 \\
\hline Communication & SRSpos3 & 75.3333 & 10.18317 & & & \\
\hline Social & & & & & & \\
\hline Motivation & SRSpos4 & 68.1667 & 12.15680 & & & \\
\hline Autistic & SRSpre5 & 81.0833 & 11.01617 & 0.12 & 0.16 & 0.54 \\
\hline Mannerisms & SRSpos5 & 72.0000 & 20.31569 & & & \\
\hline
\end{tabular}

As assessed by the TSSA.

A close observation of table 10 reveals that parent rating of post TSSA subscales show an average improvement on all of the four subscales assessing social skills, namely, perspective taking, initiating interactions, responding to initiations and maintaining interactions. A higher score on the four social skills scales indicates better social skills. Of the four pre to post test differences, all 4 adjusted $p$ scores were statistically 
significant at the 0.05 level. Effect sizes ranged from 0.34 to 0.76 on improvement of social skills as assessed by the TSSA in the camp only condition.

These results indicate that the treatment improved perspective taking skills, initiating interactions, responding to initiations, and maintaining interactions as assessed by the TSSA in the camp only condition. Effect sizes for treatment gains ranged from small to moderate. 
Table 10

Paired Sample Statistics of TSSA Social Skills scores in the Camp Condition

\begin{tabular}{|c|c|c|c|c|c|c|}
\hline & & Mean & $\begin{array}{c}\text { Std. } \\
\text { Deviation }\end{array}$ & $\begin{array}{l}\text { Raw } p \\
\text { values }\end{array}$ & $\begin{array}{c}\text { Adjusted BH } \\
\text { P values }\end{array}$ & $\begin{array}{l}\text { Effect } \\
\text { size (d) }\end{array}$ \\
\hline $\begin{array}{l}\text { Affective } \\
\text { understanding }\end{array}$ & TSSA pretest & 14.5833 & 3.42340 & 0.003 & 0.03 & 0.62 \\
\hline $\begin{array}{l}\text { Perspective } \\
\text { taking }\end{array}$ & TSSA posttest & 16.6667 & 3.20038 & & & \\
\hline Initiating & TSSA pretest & 20.1667 & 5.40763 & 0.022 & 0.05 & 0.34 \\
\hline interactions & TSSA posttest & 21.7500 & 3.81683 & & & \\
\hline Responding to & TSSA pretest & 11.2500 & 2.86436 & 0.003 & 0.03 & 0.76 \\
\hline initiations & TSSA posttest & 13.5833 & 3.20393 & & & \\
\hline Maintaining & TSSA pretest & 29.5833 & 5.90005 & 0.020 & 0.05 & 0.61 \\
\hline interactions & TSSA posttest & 33.0000 & 5.32575 & & & \\
\hline
\end{tabular}

As assessed by the TRS.

Analyses of mean scores of therapist ratings (Table 11) show that initiating interactions was the only pre to post difference statistically significant at the 0.05 level. Effect sizes ranged from 0.44 to 0.88 for improvement in social skills as perceived by clinicians on the TRS in the camp only condition.

The above results indicate that the treatment made an improvement on initiating interactions as assessed by therapists in this condition. Effect sizes for therapist observed treatment gains ranged from small to large in this treatment condition. 
In summary, parents reported significant improvements due to treatment on problem behaviors as assessed by the TSSA1 and the irritability and hyperactivity subscale of the ABC. Effect sizes for treatment gains on collateral behaviors ranged from 0.11 to 0.48 . Significant improvements were reported on social skills, as evidenced on all the subscales of the TSSA. Therapists reported significant improvement on the TRS on initiating interactions with others. Effect sizes for treatment gains on social skills ranged from 0.11 to 0.88 . 
Table 11

Paired Sample Statistics of TRS Scores in the Camp Condition

\begin{tabular}{|c|c|c|c|c|c|c|}
\hline & & & Std. & $\begin{array}{l}\text { Raw p } \\
\text { values }\end{array}$ & $\begin{array}{c}\text { Adjusted } \\
\mathrm{BH}\end{array}$ & $\begin{array}{c}\text { Effect size } \\
\text { (d) }\end{array}$ \\
\hline & & Mean & Deviation & & $P$ values & \\
\hline Initiating & TR pretest & 5.3333 & 1.96946 & 0.01 & 0.05 & 0.88 \\
\hline interactions & TR posttest & 7.0000 & 1.80907 & & & \\
\hline Maintaining & TR pretest & 5.0000 & 1.80907 & 0.03 & 0.07 & 0.68 \\
\hline interactions & TR posttest & 6.3333 & 2.05971 & & & \\
\hline Responding to & TR pretest & 6.6667 & 2.60536 & 0.08 & 0.13 & 0.44 \\
\hline others & TR posttest & 7.6667 & 2.05971 & & & \\
\hline
\end{tabular}

\section{Clinic and Camp Setting (Combined Condition)}

A paired-samples t-test was conducted to compare the pre and post scores on the 18 variables of the 4 measures in the camp condition.

Pre and Post Analysis of Problem Behaviors

A review of Table 12, indicates that of the six pre to post differences, three of the adjusted $\mathrm{p}$ scores (irritability, lethargy and problem behaviors) are significant at the 0.05 level. Effect sizes range from 0.04 to 0.66 for improvement of collateral behaviors as observed on the ABC and TSSA1 for the combined treatment condition. 
Table 12

Paired Sample Statistics of ABC and TSSA1 Scores in the Combined Condition

\begin{tabular}{|c|c|c|c|c|c|c|}
\hline & & Mean & $\begin{array}{c}\text { Std. } \\
\text { Deviation }\end{array}$ & $\begin{array}{l}\text { Raw p } \\
\text { values }\end{array}$ & $\begin{array}{c}\text { Adjusted BH } \\
\text { P values }\end{array}$ & Effect size (d) \\
\hline \multirow[t]{2}{*}{ Irritability } & $A B C$ pretest & 12.6923 & 10.16845 & 0.006 & 0.01 & 0.66 \\
\hline & ABC posttest & 7.0769 & 6.30425 & & & \\
\hline \multirow[t]{2}{*}{ Lethargy } & $\mathrm{ABC}$ pretest & 13.7692 & 8.94571 & 0.01 & 0.02 & 0.51 \\
\hline & ABC posttest & 9.6923 & 6.84817 & & & \\
\hline \multirow[t]{2}{*}{ Stereotypy } & $A B C$ pretest & 4.0000 & 3.71932 & 0.72 & 0.76 & 0.11 \\
\hline & $A B C$ posttest & 3.6154 & 3.57161 & & & \\
\hline \multirow[t]{2}{*}{ Hyperactivity } & ABC pretest & 13.3077 & 8.84482 & 0.89 & 0.89 & 0.04 \\
\hline & $A B C$ posttest & 13.0769 & 8.77935 & & & \\
\hline \multirow[t]{2}{*}{ Inappropriate } & ABC pretest & 4.4615 & 1.98391 & 0.54 & 0.61 & 0.20 \\
\hline & ABC posttest & 4.0769 & 2.17798 & & & \\
\hline \multirow{2}{*}{$\begin{array}{l}\text { Problem } \\
\text { behaviors }\end{array}$} & TSSApre1 & 60.6154 & 12.56011 & 0.000 & 0.003 & 0.61 \\
\hline & TSSApos1 & 53.0000 & 12.11060 & & & \\
\hline
\end{tabular}

These results indicate that the treatment made an improvement on problem behaviors (TSSA1) and negative behaviors such as irritability and lethargy in children in this group. Effect sizes for treatment gains ranged from small to moderate in this treatment condition. 


\section{Pre and Post analysis of Social Skills}

As assessed by the SRS

From table 13, SRS mean post $T$ score values are lower than mean pre score $T$ values indicating that parents on average reported an improvement in social skills in all of the domains of social awareness, social cognition, social communication, social motivation, and autistic mannerisms. Of the five pre to post test differences, all five of the adjusted $\mathrm{p}$ values are significant at the 0.05 level. Effect sizes ranged from 0.57 to 0.89 for improvements in social skills as indicated by the SRS in the combined condition.

These results suggest that the combined treatment of both camp and clinic made a significant improvement on social awareness, social cognition, social communication, social motivation, and autistic mannerisms of children in this group. Treatment gains of social skills, as assessed by the SRS for the combined condition, ranged from moderate to large. 
Paired Sample Statistics of SRS scores in the Combined Condition

\begin{tabular}{|c|c|c|c|c|c|c|}
\hline & & Mean & $\begin{array}{c}\text { Std. } \\
\text { Deviation }\end{array}$ & $\begin{array}{l}\text { Raw } p \\
\text { values }\end{array}$ & $\begin{array}{c}\text { Adjusted } \\
\text { BH } \\
\text { P values }\end{array}$ & Effect size (d) \\
\hline Social & SRS pretest & 78.1538 & 11.05174 & 0.005 & 0.01 & 0.68 \\
\hline Awareness & SRS posttest & 71.0000 & 9.65229 & & & \\
\hline Social & SRS pretest & 85.2308 & 8.21740 & 0.01 & 0.03 & 0.57 \\
\hline Cognition & SRSpos2 & 79.6923 & 10.98776 & & & \\
\hline Social & SRSpre3 & 83.6154 & 8.21116 & 0.02 & 0.03 & 0.89 \\
\hline \multicolumn{2}{|c|}{ Communication SRSpos3 } & 77.3077 & 5.57352 & & & \\
\hline Social & SRSpre4 & 74.5385 & 10.28442 & 0.04 & 0.05 & 0.57 \\
\hline Motivation & SRSpos4 & 68.4615 & 10.54842 & & & \\
\hline Autistic & SRSpre5 & 87.7692 & 4.65750 & 0.03 & 0.05 & 0.59 \\
\hline Mannerisms & SRSpos 5 & 84.3077 & 6.71298 & & & \\
\hline
\end{tabular}

As assessed by the TSSA.

Table 14 indicates that of the four pre to post test differences on parent ratings of the TSSA, three (perspective taking, responding to initiations and maintaining interactions) of the adjusted $\mathrm{p}$ values are significant at the 0.05 level. Effect sizes range from 0.34 to 1.08 for improvement in social skills as assessed by the TSSA in the combined condition. 
These results suggest that the treatment made a significant improvement in perspective taking skills, responding to initiations and maintaining interactions as assessed by the TSSA in the combined condition. Effect sizes for treatment gains ranged from small to large on this measure in this treatment condition. 
Table 14

Paired Sample Statistics of TSSA scores in the Combined Condition

\begin{tabular}{|c|c|c|c|c|c|c|}
\hline & & Mean & $\begin{array}{c}\text { Std. } \\
\text { Deviation }\end{array}$ & $\begin{array}{l}\text { Raw } p \\
\text { values }\end{array}$ & $\begin{array}{c}\text { Adjusted } \mathrm{BH} \\
\mathrm{P} \text { values }\end{array}$ & $\begin{array}{c}\text { Effect size } \\
\text { (d) }\end{array}$ \\
\hline $\begin{array}{l}\text { Affective } \\
\text { understanding }\end{array}$ & TSSA pretest & 14.0000 & 2.97209 & 0.006 & 0.01 & 0.95 \\
\hline $\begin{array}{l}\text { Perspective } \\
\text { taking }\end{array}$ & TSSA posttest & 17.6923 & 4.60769 & & & \\
\hline Initiating & TSSA pretest & 23.6154 & 5.33133 & 0.14 & 0.17 & 0.34 \\
\hline interactions & TSSA posttest & 25.8462 & 7.38067 & & & \\
\hline Responding to & TSSA pretest & 13.5385 & 2.84650 & 0.02 & 0.04 & 1.08 \\
\hline initiations & TSSA posttest & 16.3077 & 2.21302 & & & \\
\hline Maintaining & TSSA pretest & 27.6923 & 3.06552 & 0.01 & 0.02 & 1.04 \\
\hline interactions & TSSA posttest & 35.5385 & 10.12929 & & & \\
\hline
\end{tabular}

As assessed by the TRS.

Analysis of mean scores of therapist ratings (Table15) show that ratings improved on post scores on the three subscales, initiating interactions, maintaining interactions, and responding to others. Of the three pre to post test differences, all three adjusted $p$ values are significant at the 0.05 level. Effect sizes range from 0.79 to 0.93 for improvement of social skills, as perceived by clinicians in the combined treatment condition. 
The above results suggest that the combined treatment had a significant improvement on initiating, responding to, and maintaining interactions, as assessed by therapists in this condition. Treatment gains from therapist observations and ratings show large effect sizes.

In summary, parents reported significant improvements due to treatment on the irritability and lethargy subscale of the $\mathrm{ABC}$ and problem behaviors subscale on the TSSA. Effect sizes ranged from small to moderate $(0.04$ to 0.66$)$. Significant improvements in social skills were observed on all subscales of the SRS and three of the four subscales on the TSSA. Therapists reported significant improvement on the TRS on initiating, responding to, and maintaining interactions with others. Effect sizes for treatment gains on social skills ranged from 0.34 to 1.08 . 
Table 15

Paired Sample Statistics of TRS scores in the Combined Condition

\begin{tabular}{|c|c|c|c|c|c|c|}
\hline & & Mean & Std. Deviation & Raw $p$ values & $\begin{array}{c}\text { Adjusted BH } \\
\text { P values }\end{array}$ & Effect size (d) \\
\hline Initiating & TR pretest & 6.4615 & 3.07179 & 0.002 & 0.01 & 0.79 \\
\hline interactions & TR posttest & 8.6154 & 2.21880 & & & \\
\hline Maintaining & TR pretest & 5.5385 & 2.60177 & 0.002 & 0.01 & 0.93 \\
\hline interactions & TR posttest & 7.6923 & 1.97419 & & & \\
\hline Responding to & TR pretest & 8.3077 & 1.97419 & 0.007 & 0.01 & 0.89 \\
\hline others & TR posttest & 10.1538 & 2.07550 & & & \\
\hline
\end{tabular}

\section{Group Effect}

An Analysis of Variance (ANCOVA) was used to test the effects of the categorical variables (group) on the 18 dependent variables. Before conducting the ANCOVAs, the homogeneity of regression assumption was first tested. A significant interaction between the covariate and the group suggests that the differences on the dependent variable among groups vary as a function of the covariate. A significant interaction was obtained on three of the dependent variables: (a) inappropriate speech on the $\mathrm{ABC}$, (b) social communication on the SRS and (c) responding to initiations on the TSSA. Excluding these three dependent variables, separate ANCOVAs were run on the 15 other dependent variables where the assumption of homogeneity-of-regression was met. The results of the ANCOVA demonstrating the effect of group on the 15 dependent variables are summarized in Table16. 
Table16

ANCOVAs Demonstrating the Effect of Group on the Dependent Variables

$\begin{array}{llllll}\text { Dependent } & \text { Source } & \text { df } & \text { Mean square } & \text { F } & \text { Sig. }\end{array}$

Variable

\begin{tabular}{llllll}
\hline $\mathrm{ABC}$ & group & 2 & 27.760 & 2.487 & .099
\end{tabular}

Irritability

\begin{tabular}{llllll}
\hline $\mathrm{ABC}$ & group & 2 & 21.836 & 2.165 & .131
\end{tabular}

Lethargy

\begin{tabular}{llllll}
\hline $\mathrm{ABC}$ & group & 2 & 4.081 & .600 & .555
\end{tabular}

Stereotypy

\begin{tabular}{llllll}
\hline $\mathrm{ABC}$ & group & 2 & 23.175 & 1.257 & .298
\end{tabular}

Hyperactivity

\begin{tabular}{llllll}
\hline SRS Social & group & 2 & 22.475 & .492 & .616
\end{tabular}

Awareness

\begin{tabular}{llllll}
\hline SRS Social & group & 2 & 53.210 & 1.177 & .321
\end{tabular}

Cognition

\begin{tabular}{llllll}
\hline SRS Social & group & 2 & 82.725 & 1.937 & .160
\end{tabular}

Motivation

\begin{tabular}{llllll}
\hline SRS Autistic & group & 2 & 202.494 & 1.415 & .257
\end{tabular}

Mannerisms

\begin{tabular}{llllll}
\hline TSSA & group & 2 & 26.808 & .374 & .691
\end{tabular}

Behavior

problems 


\begin{tabular}{llllll}
\hline TSSA & group & 2 & 32.879 & 3.206 & .053
\end{tabular}

Perspective

taking

\begin{tabular}{llllll}
\hline TSSA & group & 2 & 7.896 & .443 & .646
\end{tabular}

Initiating

interactions

\begin{tabular}{llllll}
\hline TSSA & group & 2 & 56.497 & 1.239 & .303
\end{tabular}

Maintaining

Interactions

\begin{tabular}{llllll}
\hline TRS Initiate & group & 2 & 5.640 & 1.922 & .162
\end{tabular}

interactions

\begin{tabular}{llllll}
\hline TRS Maintain & group & 2 & 3.804 & 1.293 & .288
\end{tabular}

interactions

\begin{tabular}{llllll}
\hline TRS & group & 2 & 6.913 & 2.464 & .101
\end{tabular}

Responding to

others

As noted in Table16, 15 separate ANCOVAs were conducted with group as the independent variable (clinic only, camp only and combined condition); the post values on the 15 subscales of the four measures as the dependent variables; and the prescores of the measures as the covariates. The ANCOVAs show that group setting (camp only, clinic only or the combined condition) was not significant for any of the dependent variables.

Analysis of the 15 different profile plots is further summarized in Table 17. The three group settings are ranked in order of improvement on the 15 dependent measures 
with adjusted prescores (covariates) minimizing the error variance across the three groups.

From table17, it is evident that the combined condition showed the most improvement on 11 of the 15 dependent variables when the prescores were adjusted for error variance

In summary, 15 separate ANCOVAs were conducted to evaluate the effect of group on the dependent measures. The independent variable of group setting was not found to be significant for any of the dependent variables tested, thus, accepting the null hypothesis that there will be no difference in pre and post scores as a result of treatment condition. Analysis of profile plots on the ANCOVAs indicated that the combined condition (camp and clinic) showed most improvement over the other two treatment conditions (camp only and clinic only) on 11 of the 15 dependent measures. 
Table 17

Summary of Profile Plots Showing Effect of Group on the Dependent Measures

\begin{tabular}{|c|c|c|c|}
\hline Dependent & Rank \#1 & Rank \#2 & Rank \#3 \\
\hline Measure & Most Improved & Next Improved & Least Improved \\
\hline$\overline{\mathrm{ABC}}$ & Combined & Clinic only & Camp only \\
\hline Irritability & condition & & \\
\hline $\mathrm{ABC}$ & Combined & Camp only & Clinic only \\
\hline Lethargy & condition & & \\
\hline$\overline{\mathrm{ABC}}$ & Clinic only & Combined & Camp only \\
\hline Stereotypy & & condition & \\
\hline $\mathrm{ABC}$ & Clinic only & Camp only & Combined \\
\hline Hyperactivity & & & condition \\
\hline SRS Social & Combined & Camp only & Clinic only \\
\hline Awareness & condition & & \\
\hline$\overline{\text { SRS Social }}$ & Clinic only & Combined & Camp only \\
\hline Cognition & & Condition & \\
\hline SRS Social & Combined & Camp only & Clinic only \\
\hline Motivation & condition & & \\
\hline SRS Autistic & Camp only & Combined & Clinic only \\
\hline Mannerisms & & condition & \\
\hline TSSA Behavior & Combined & Clinic only & Camp only \\
\hline problems & condition & & \\
\hline TSSA Perspective & Combined & Camp only & Clinic only \\
\hline
\end{tabular}




\begin{tabular}{llll}
\hline taking & condition & & \\
\hline TSSA Initiating & Combined & Clinic only & Camp only \\
interactions & condition & & \\
\hline TSSA Maintaining & Combined & Clinic only & Camp only \\
Interactions & condition & & \\
\hline TRS Initiate & Combined & Camp only & Clinic only \\
interactions & condition & & \\
\hline TRS Maintain & Combined & Clinic only & Camp only \\
interactions & condition & & \\
\hline TRS Responding to & Combined & Clinic only & Camp only \\
others & condition & & \\
\hline
\end{tabular}

\section{Summary of Results}

Pre to post differences were analyzed in each treatment setting. Greater number of significant $p$ values and magnitude of effect sizes were obtained in the combined condition, followed by the camp only condition and, lastly, the clinic condition. Effect sizes were positively correlated with treatment time at the 0.05 level, indicating that additional treatment led to greater effect sizes. Criterion measures such as the TSSA showed greater effect sizes in social skills treatment gains than the SRS. The problem behavior subscale of the TSSA was similar to the activity subscales of the ABC, such as the lethargy and hyperactivity subscale, in terms of observed effect sizes and statistical significance attained. 
While greater treatment gains were observed in the combined condition, followed by camp only and then clinic only condition, these treatment differences across the three groups were not statistically significant, as determined by the ANCOVAs. Analysis of profile plots in the ANCOVAs, when group differences were adjusted for error variance, show that the combined condition led the other two conditions in terms of improvement on social skills and related behaviors. 


\section{CHAPTER V}

\section{DISCUSSION}

The results and future implications of this study are discussed in this chapter. The discussion includes (a) overall findings and implications, (b) limitations, and (c) future research opportunities. An emphasis is placed on analyzing the functional contribution of these results to future social skills training of children with ASD and exploring future research ideas.

\section{Overall Findings and Implications}

Identifying social skills deficits in ASD and corresponding behaviors as a result of these deficits was elicited from extensive research/literature reviews and clinical experience with the ASD population. Teaching strategies and supports were based on evidence-based recommendations as reviewed in Chapter II. The unique aspect of this study that sets it aside from all other studies in social skills training of children with ASD is the simultaneous study of the contexts in which the training was carried out. A specific emphasis was placed on generalization of skills through parent training and environmental modifications such as inclusion of typical peers to facilitate practice. Thus, this study adds to the research base for carrying out an evidence-based social skills training program within traditional and natural environmental contexts such as a camp. 
In examining group effect, when pre scores were adjusted for error variance, the ANCOVAs did not show a significant treatment effect. This was unexpected, as one would assume that the combined treatment condition would undoubtedly be superior in terms of hours of direct intervention and the combination of parent training and facilitation of skills by clinicians. One explanation could be that treatment ingredients in all three conditions were effective as noted by effect sizes, but not significantly different from each other. Statistical significance could also have been affected by the small sample size in this study. A larger sample size may have resulted in different results. While more significant treatment gains are reported in the combined condition, as well as greater effect sizes, the gains are not significant enough to definitively say, at this point, and with this sample that the combined treatment is superior over the other two, or that camp is significantly better than the clinic condition.

Although the three groups did not significantly differ from each other, analysis of profile plots from the ANCOVAs show that when the pre-scores are adjusted for error variance, the combined condition does lead the camp only or clinic only condition in terms of improvement on social skills and related behaviors. The combined treatment condition was superior to the clinic only or camp only treatments in terms of effect sizes and statistical significance of dependent variables for behavior and social skills improvements. The greater effect sizes and significance of improvement on the subscales in the combined condition, as compared to the clinic only or camp only conditions, can be attributed to dosage levels (intervention consisting of sixty to sixty two hours). The combined condition had the benefit of more thorough parent training, as well as the facilitation of skills through the day by clinicians at camp. 
Pre and post analysis of related behaviors in the combined context reveal significant improvements on Irritability and lethargy subscales of the $A B C$ and the problem behavior subscale of the TSSA. In all three treatment conditions significant improvements are noted on activity levels (hyperactivity and lethargy) and the irritability scale of the ABC. Tse, et al., (2007) also found the largest effect size on the "irritability" scale of the ABC. In their study, age had a significant effect on out come on the "Irritability" subscale where greater improvements were found for subjects age 14 and under. In this study, all subjects were 14 and under and for this group, change in activity levels and mood are more noticeable and appear to be more susceptible to improvements than features such as inappropriate speech or stereotypy. In this condition both SRS and TSSA noted significant improvements on social skills. The combined condition is the only condition where the SRS showed significant improvements on its subscales.

The clinic context in this study when compared to other studies (Tse, et al., 2007) that utilized clinic samples is comparatively shorter. In this case post treatment gains were not significant, yet small to moderate effect sizes were obtained. Effect sizes are independent of sample size and clearly indicate that despite lack of statistical significance (which was affected by sample size and adjustments based on multiple comparisons) moderate treatment gains were accomplished in the clinic context. As noted earlier, results could have been very different if a larger sample and a single measure had been utilized. Based on statistical significance alone to say the clinic based intervention had no effect would be considered making a type 1 error. Moderate effect sizes were found on the $\mathrm{ABC}$ with regard to hyperactivity and inappropriate speech. On the SRS moderate gains are noted on the social cognition subscale. On the TSSA, moderate to large gains 
are noted on problem behaviors and maintaining interactions. On the TRS, moderate gains are found on initiating and responding to others. It is interesting to note that the two social skills measures picked up on two different aspects of social skills measured. The SRS shows most gains on aspects pertaining to picking up on social cues while the TSSA shows gains on maintaining social interactions. These differences may be attributed to the wording or manner in which statements are expressed in the two different questionnaires and parent understanding of these terms. Inconsistent outcomes on measures are also not unique in psychosocial intervention research (Achenbach, 2004; De Les Royes and Kazdin, 2006). While the TSSA described earlier is a criterion-based measurement and is more specific to the goals of the intervention, the SRS is a standardized instrument intended to capture social skills deficits specific to autism but at a more global level.

Parent training was offered within the clinic context, which was the shortest training program of the three contexts examined in this study, as well as when compared to other social skills training programs reviewed and comprised of a total of 10 to 12 hours of direct instruction. Number of intervention hours for this sample was dictated by third-party payers and the structure of managed care. Most research in ASD interventions reviewed has occurred in contexts such as school or university-based settings and as part of a research protocol (Rogers, 2000) and there is very little guidance on strategies to move evidence-based practices into everyday clinical settings (Howlin \& Yates, 1999) where children with ASD are users of behavioral health services. It is imperative then to provide a cost effective, time limited yet comprehensive evidence-based treatment program that benefit children with ASD. Therefore an added component to the traditional clinic setting was the simultaneous training of parents and their ability to view the entire 
training session through a one-way mirror, have access to all training materials and thus to facilitate their children completing the required homework for each session based on the topic under study. Parent training involving observation of the training program is a unique factor and has only been reviewed in one study to date (Ruble, Willis and Crabtree, 2008). It also added the generalization component where after viewing the methods used to teaching social skills, parents could use the same strategies to teach their children in other environments as well.

\section{Relationship of Results to Generalization Through Parent Training}

Given the environment we provide clinical services for individuals on the autism spectrum where time and length of services are often mandated by third party payers, it is often necessary to provide the needed services in an effective manner within a limited time frame. This study compared three different intervention contexts, each with varying time frames and while it established that more intervention did produce more widespread improvements, it also established the fact that a simple low cost intervention can also be beneficial to individuals with ASD.

Several studies reviewed in chapter two did not show generalization of skills to other contexts (Ozonoff and Miller, 1995; Trimarchi, 2004; Rose and Anketell, 2009). Small to moderate effect sizes were obtained within the clinic context in this study which only consisted of 10 to 12 hours and considerably shorter in duration when compared to studies previously reviewed. The unique aspect of the clinic context when compared with aforementioned studies, was the simultaneous parent training component incorporating direct observation of the social skills training. 
It is a known fact that children with ASD do not generalize very well to other contexts (Dunlap \& Plienis, 1988; Fowler, 1988; Sailor, Goetz, Anderson, Hunt, \& Gee, 1988), it is important to ensure that every effort is made to incorporate this essential ingredient. As noted earlier, a successful program should incorporate mechanisms for enhancing performance of previously acquired skills in naturalistic settings using manipulation of antecedents such as peer tutoring, incidental teaching or manipulation of consequences including differential reinforcement (Gresham, Sugai and Horner 2001). Often it is not feasible for the clinician to be a trainer and be present in the natural contexts of the child with ASD. Thus, it is crucial to consider other factors to promote generalization to other contexts.

Historically, parent training was first emphasized by Lovaas and his colleagues when they noted that following intensive treatment, children whose parents were trained to carry on the intervention continued to make gains (Lovaas, Koegel, Simmons, \& Long, 1973). Since then parent intervention has found to increase generalization and maintenance of skills over time (e.g., Koegel, Schreibman, Britten, Burke, \& O’Neill, 1982). Despite these findings there are few studies in literature that incorporate a parent training component formally within the intervention plan that includes social skills training of youth with ASD. Two studies (Largeson, Frankel and Mogul, 2009; Frankel, Myatt, Sugar, et al., 2010) examined the efficacy of a manualized parent-assisted social skills intervention in comparison with a matched Delayed Treatment Control group to improve friendship quality and social skills among teens and younger children with high functioning autism and Aspergers Disorder. Both studies showed that the treatment group 
significantly improved their knowledge of social skills, increased frequency of hosted get-togethers, and improved overall social skills as reported by parents.

In this study parents were trained in the clinical context to further skills to other environments. As a control group was not utilized in this study, it cannot be determined that the parent training component was solely responsible for the small to moderate treatment gains in the clinic only context. However, if interventions are to be provided within a clinic context, as noted earlier, for the intervention to be effective there needs to be a mechanism employed for the carry over of skills from the clinic to other contexts. When parents and siblings are taught to employ naturalistic interventions that could be construed as very similar to their normal everyday interactions there is potential for a treatment program to have far reaching positive effects. (Baker, 1989; Daurelle, Fox, MacLean, \& Kaiser, 1987, Graziano \& Diament, 1992; Polster, Dangel, \& Rasp, 19861987; Schaefer \& Briesmeister, 1989; Tiedemann, Georgia, \& Johnston, 1992; WebsterStratton \& Hammond, 1990; Webster-Stratton, Hollinsworth, \& Kolpacoff, 1989).

\section{Relationship of Results to Use of Natural Contexts}

Summer programs and camps as evidenced in this study showed promising results in targeting social skills and behavior in children with ASD. Camp was originally developed to provide a fun social context for children with ASD. While camp is not approved for third-party payer benefits, several philanthropic organizations sponsored the event and reduced the financial burden for families.

Social skills training was introduced within the camp setting to provide training within a natural context, utilize typical peers and intensify the treatment through training and facilitation of practice through the day. However camp did not include a structured 
parent training program. Parents met with clinicians on a regular basis to discuss the skill reviewed and received the handouts but they did not get the training in terms of implementing the supports and facilitating practice in other environments.

Pre to post differences of treatment gains in the camp only condition show small to large effect sizes and gains superior to the clinic only condition. When compared to other studies reviewed of similar duration but spread over months (Ozonoff and Miller, 1995; Provencal, 2003; Solomon, et al., 2004; Cotugno, 2009) camp condition does just as well or better in terms of generalization, as reported by parents with regard to social skills and related behaviors. Irritability and hyperactivity measures on the $\mathrm{ABC}$ show significant improvement, as well as all the measures on the TSSA and initiating interactions on the TSA. Some degree of similarity was found on the improvements noted in terms of effect size within the clinic and camp contexts. Hyperactivity shows more improvement on the behavior scales in both conditions. As noted earlier, activity levels are more often noticed as indices of change than factors such as stereotypy. Maintaining interactions also shows improvement in terms of effect size in both conditions. Unique to the camp setting, however, is the significant improvement on all social skills subscales of the TSSA that are not reflected on the SRS. Once again, a plausible explanation for this inconsistency could be the specificity of items on the TSSA to the intervention.

This study indicates that more robust treatment gains (as compared to the clinic setting) are detected when treatment is offered within the child's natural environment as compared to a clinic only condition. Providing social skills intervention in naturalistic contexts raises the question of implementing such interventions within the classroom and 
the social context of school. Bellini et al., (2007) found statistically significant differences between interventions implemented in the child's typical classroom and studies implemented in pullout settings. That is, studies implemented in the child's typical classroom setting produced significantly higher intervention maintenance, and generalization effects than interventions that involved removing the child from the classroom. Social skills training within the regular classroom is often not feasible given the challenges involved in teaching children with autism (Ruble \& Dalrymple, 1996). Research conducted by the British Columbia Teacher Federation (Leblanc, Richardson and Burns 2009) focused specifically on teachers' views as they related to special education in general. One of the main areas of contention highlighted by the survey respondents concerned itself with the lack of preparation for instructing in a class that included a new and unfamiliar category of "special need" (i.e., ASD). In addition teachers and resource teachers reported high levels of stress when left to cope with exceptional students with low levels of support.

In short, reducing stress and anxiety within a model that currently requires boards of education, schools, and classrooms to make adaptations based on the unique and individual needs of the students will require all educational stakeholders to have at least a working knowledge of ASD and some general idea as to how social skills training can be effectively programmed for in the "regular" classroom environment.

\section{Relationship of Results to Valid Outcome Measures}

This study utilized four outcome measures. Two standardized measures (ABC and SRS) to assess change in behavior and social skills to facilitate comparisons with other 
studies and two criterion based measures (TSSA and TRS) to detect specific changes targeted by the social skills curriculum employed in this study.

Most studies found in social skills training literature have employed the Social Skills Rating System (SSRS; Gresham and Elliott, 1990). Most studies that used the SSRS did not show change with treatment, probably because the measure is not appropriate for assessing the impact of such interventions in children with ASD. The SSRS measures broad based behaviors associated with developing social skills but does not assess the nuances of behaviors associated with social reciprocity that are lacking in children with ASD (White, Koenig, \& Scahill, 2007). To avoid similar pitfalls this study selected the SRS and ABC which are more relevant to ASD and are reported to be sensitive to change with treatment. The TSSA and TRS are criterion measures specific to social reciprocity as well (initiating, responding, maintaining interactions). The TSSA included the problem behavior subscale. Scores on this subscale corresponded to the hyperactivity and Irritability subscales on the $\mathrm{ABC}$.

Pre to post comparisons on the four measures showed that while nearly all post scores showed gains, statistical significances and effect sizes varied on the different subscales, with the criterion related measures on the whole showing greater effect sizes and statistical significances than the standardized measures. The criterion measures, as noted earlier, were more specific to the intervention, while the standardized instruments were more global in nature.

Results were also surprisingly inconsistent. While the TSSA showed significant gains in maintaining interactions in some conditions, similar gains were not observed on the SRS measure of social communication. In the psychological sciences, inconsistent 
results following intervention research have been consistently noted (Achenbach 2006;

De Los Reyes \& Kazdin, 2006). The possible source of variation in outcome in group social skills training is the focus of treatment that is social reciprocity, an extraordinarily complex, multidimensional construct. This continues to present a unique challenge for intervention research and evaluation of outcomes in social skills training.

It is imperative to use multiple measures and modalities of assessment in examining a complex construct such as social reciprocity. Specificity regarding the estimated effect of the intervention on different aspects of the impairment requires the use of multiple indicators of change. In this study multiple outcome measures were used as recommended by Herschell, McNeil and McNeil (2004) and De Los Reyes and Kazdin (2006).

\section{Study Limitations}

This study was limited by a number of factors, including a small sample size and the absence of a control group. The absence of a control group leaves unanswered the question of whether positive results are due to test attenuation or spontaneous improvement versus to group participation. Smaller sample size affected the overall power and statistical significance attained on the dependent variables. As such, some findings appear to be specific to the intervention. For example, higher dosage levels of treatment led to larger effect sizes and a greater number of significant improvements on the dependent variables. Effect sizes were comparable to previous studies that utilized a control group (Provencal, 2003; Tse et al., 2007).

The social skills groups were offered in response to a clinical need and participants were not recruited for research but referred by treating clinicians. Formal 
recruitment efforts will be necessary to perform a larger study, particularly if randomization to treatment and control groups is desired. The current study selected 12 subjects from each treatment condition based on age and screening measures utilized by the TSSA. More accurate description of the sample, such as IQ, is desirable but was unavailable for all participants. Cognitive functioning could play a role in degree of improvement achieved, and treatment groups may have been uneven on this aspect. The ANCOVAs were specifically selected to study between group effects and to offset the possibility of non- equivalent groups.

Another limitation of the study was the use of only parent report measures to test for quantitative evidence of generalized improvement. Teachers may have had different perceptions regarding changes in subjects' social and related behaviors. Access to teachers was unavailable in the summer months and thus it was not possible to incorporate teacher perceptions of change in this study. Furthermore it is not possible to know whether treatment gains were maintained as follow up data is not available.

Medication use was not monitored over the course of the treatment groups within the different contexts. In a previous study (Tse et al., 2007) no differences were found between outcomes for subjects taking versus not taking medications. However medication effects cannot be entirely ruled out as a confounding variable in this study.

While the treatment program was manualized and all clinicians were trained in the use of the manual, a formal fidelity measure such as a fidelity checklist was not incorporated within the manual. Fidelity was monitored informally through verbal feedback of clinicians and random observation of groups. Clinicians working with the 
groups had extensive experience working with children on the spectrum and had conducted numerous groups and camps prior to this study.

Parent training was a unique feature of the clinic only condition. However, a measure was not utilized to study parent empowerment and transfer of skills learned in these sessions in other environments. This information could have provided more knowledge in the utilization of parent training programs in future social skills training programs.

\section{Future Research Options}

Group based social skills training continues to remain understudied, but is certainly worthy for further development and testing, given the socialization deficits in youth with ASD and the negative impact that such deficits have on all aspects of development.

The limitations underscored in this study give direction for future studies. Use of larger samples with random assignment to treatment and control groups will further validate effects of social skills group training. The manualized curriculum used in this study could be used and tested in other sites to demonstrate reliability and evaluation of fidelity. Multiple informants, especially the use of blinded independent evaluators and reliable outcome measures sensitive to change if used across sites will accrue sufficient sample sizes to evaluate the impact of a treatment in a randomized study. Randomized control trials are becoming increasingly important to psychosocial intervention research as in medical research (Lord, Wagner, and Rogers et al., 2005; Smith et al., 2006).

A major thrust in this study that sets it apart from other group social skills training studies as previously mentioned are the factors used to promote generalization through 
parent training and use of natural contexts to implement the training. Future studies need to more thoroughly research these variables as it may have the potential to change the course of social skills group intervention methods.

Relative to parent training research, consideration should be given to the tremendous stress on parents with children on the autism spectrum due to insufficient support systems (Ramey and McPhee, 1986; Seifer, Sameroff, Baldwin, et al., 1992). A wide variability could surface in terms of how parents respond to their child with ASD and their readiness to implement treatment strategies in the home and other contexts. Therefore, it might be prudent to establish parent readiness prior to starting interventions with parents. Future research options should consider developing reliable measures to ascertain parent readiness to implement interventions with their child. Manualized parentbased treatment methods should address topics that deal with stress management, advocating for their child effectively and successfully overcoming obstacles that impede implementation of intervention techniques.

The question of generalization of skill sets to other contexts then raises the question of implementing intervention techniques in other natural contexts such as camps and classrooms. In the camp context of this study, para professionals and students were trained to engage and implement intervention strategies with students with ASD in a brief and cost effective manner. The question then is can similar trainings be implemented within a school setting targeting teachers, paraprofessional and appropriate typical peers to mediate interventions in an unobtrusive manner targeting students with ASD? Mazurik-Charles and Stefanou (2010) in their non randomized sample of seven children with ASD showed that social skills training provided by paraprofessionals in both 
partially and fully included classrooms can result in perceived gains in social skills as measured by teacher ratings. Their results revealed that several areas of social responsiveness noticeably improved as a result of the intervention in the short run. However, sustained improvement was difficult to detect. In this study, paraprofessionals received a two hour training prior to start of interventions and were observed and coached as needed. Tremendous potential lies in continuing and furthering this line of research. Teacher aides and other therapists directly involved with the targeted ASD child due to IEP (Individualized Education Plans) requirements can be trained to implement strategies and intervention techniques in the classroom or playground in an inconspicuous manner.

A similar intervention structure used at camp can be implemented within a school setting. Targeted children with ASD could receive individual or group training from a therapist such as a guidance counselor, special educator, speech or occupational therapist. Incorporation of strategies in the classrooms can be facilitated by a teacher aid, playground or lunch supervisor.

\section{Concluding Summary}

Overall the findings of this study show that when a comprehensive, manualized social skills training program is applied within a group format, observed and generalized improvements are noted in targeted social skills and related behaviors. Degree of improvement was related to duration of treatment. Context of intervention played an important but not significant role in differentiating between the three treatment groups. The combined context which consisted of both clinic and camp based interventions showed most number of significant improvements on the dependent measures, followed by the camp context and finally the clinic context. Improvements in the clinic based 
intervention were not significant however small to moderate effect sizes were noted. These improvements cannot be ignored in light of the brevity of this program when compared to previous research in group social skills training (Ozonoff and Miller, 1995; Trimarchi, 2004). In comparison to similar studies reviewed, the exceptional factor in the clinic based intervention was the parent training component that could have played a role in the generalization of skills.

The camp context provided social skills training within the child's natural environment using peer mediated strategies and trained graduate and high school students. Camp was a better alternative than the clinic only based intervention in terms of number of significant improvements across the number of dependent variables and increase in treatment gains as measured by effect sizes. Based on parent and child report camp was also a more fun and enjoyable experience.

The combined model where children attended both clinic and camp interventions showed most number of significant improvements and greater effect sizes when compared to camp and clinic only interventions. However analysis of covariance between groups did not show a particular context to be significantly better than another context.

This is one of few studies in social skills group training that employed a parent training component. This study raises the issue of facilitating generalization of skills to other contexts through parent training and recommends future research exploring variables that affect parent training such as parent readiness.

The study also conducted group social skills intervention within the child's natural environment and recommends future research initiatives to explore options to implement social skills training within the natural context such as the class room setting. 
Social skills deficits in children with ASD impact all aspects of development and have devastating consequences affecting their emotional, academic and social well being. Providing an effective treatment program to those affected is crucial and critical. This study is a step forward in providing an overview of a comprehensive intervention that can be provided in a clinic or natural setting. 


\section{REFERENCES}

Achenbach, T. (2006). As others see us: Clinical and research implications of crossinformant correlations for psychopathology. Current Directions in Psychological Science, 15(2), 94-98.

Aman, M. G., Singh, N. N., Stewart, A. W., \& Field, C. J. (1985). The aberrant behavior checklist: A behavior rating scale for assessment of treatment effects. Journal of Mental Deficiency, 89, 485-491.

Bader, R. (2006). Using social stories to increase emotion recognition and labeling in school-age children with autism. Dissertation Abstracts International, 67, Retrieved from PsycINFO database.

Baker, J. N. (1989). Therapeutic foster parent: Professionally or emotionally involved parent? Child and Youth Services, 12, 149-157.

Baker, J. (2003). Social skills training. Kansas: Autism Asperger Publishing, Co.

Barnhill, G. P., Cook, K. T., Tebbenhamp, K., \& Myles, B. S. (2002). The effectiveness of social skills intervention targeting nonverbal communication for adolescents with asperger syndrome and related pervasive developmental delays. Focus on Autism and Other Developmental Disabilities, 17, 112-118.

Baron-Cohen, S., Tager-Flusberg, H., \& Cohen, D. (2000). Understanding other minds: Perspectives from cognitive neuroscience. New York: Oxford University Press. 
Baron-Cohen, S. \& Wheelwright, C. (2004). The Empathy Quotient (EQ). An investigation of adults with Asperger Syndrome or High Functioning Autism, and normal sex differences. Journal of Autism and Developmental Disorders, 34, $163-175$.

Barry, T. D., Klinger, L. G., Lee, J. M., Palardy, N., Gilmore, T., \& Bodin, S. D. (2003). Examining the effectiveness of an outpatient clinic-based social skills group for high-functioning children with autism. Journal of Autism and Developmental Disorders, 33, 685-701.

Bauminger, N., \& Kasari, C. (2000). Loneliness and friendship in high-functioning children with autism. Child Development, 71(2), 447.

Bauminger, N. (2007). Brief report: Group social-multimodal intervention for HFASD. Journal of Autism and Developmental Disorders, 37, 1605-1615.

Begeer, S., Koot, H., Rieffe, C., Terwogt, M., \& Stegge, H. (2008). Emotional competence in children with autism: Diagnostic criteria and empirical evidence. Developmental Review, 28(3), 342-369.

Bellini, S., Peters, J., Benner, L., \& Hopf, A. (2007). A meta-analysis of school-based social skills interventions for children with autism spectrum disorders. Remedial and Special Education, 28(3), 153-162.

Bloomquist, M. (2006). Skills training for children with behavior problems New York: The Guilford Press.

Bodfish, J. W. (2004). Treating the core features of autism: Are we there yet? Mental Retardation and Developmental Disabilities Research Reviews, 10, 318-326. 
Borden, M. C., \& Ollendick, T. H. (1994). Examination of the validity of social subtypes in autism. Journal of Autism and Developmental Disorders, 24, 23-37.

Brown, E. C., Aman, M. G., \& Havercamp, S. M. (2002). Factor analysis and norms for parent ratings on the aberrant behavior checklist - community for young people in special education. Research in Developmental Disabilities, 23, 45-60.

Brown,W. H., Odom, S. L., Conroy,M. A. (2001). An intervention hierarchy for promoting young children's peer interactions in natural environments. Topics in Early Childhood Special Education, 21, 162-175.

Buggey, T. (1999). Using videotaped self-modeling to change behavior. Teaching Exceptional Children. March/April, 27-30.

Capps, L., Sigman, M., \& Yirmiya, N. (1996). Self-competence and emotional understanding in high-functioning children with autism. Development and Psychopathology, 7, 137-149.

Carnine, D. (1995). Using research to bolster student learning. School Administrator, 52, $10-14,16$.

Carter, A. S., Davis, N. O., Klin, A., \& Volkmar, F. R. (2005). Social development in autism. In F. R. Volkmar, R. Paul, A. Klin, \& D. Cohen (Eds.), Handbook of autism and pervasive developmental disorders: Vol. 1. Diagnosis, development, neurobiology, and behavior. Hoboken, NJ: John Wiley \& Sons.

Chamberlain, B. O. (2001). Isolation or involvement? The social networks of children with autism included in regular classes. (Unpublished doctoral dissertation). University of California, Los Angeles. 
Charlop-Christy, M. H., \& Daneshvar, S. (2003). Using video modeling to teach perspective taking to children with autism. Journal of Positive Behavior Interventions, $5,12-21$.

Constantino, J. N., \& Gruber, C. P. (2005). Social responsiveness scale. Los Angeles: Western Psychological Services.

Constantino, J. N., Przybeck T., Friesen, D., \& Todd, R. D. (2000). Reciprocal social behavior in children with and without pervasive developmental disorders. Journal of Behavioral Pediatrics, 21, 2-11.

Constantino, J., Davis, S., Todd, R., Schindler, M., Gross, M., Brophy, S., et al. (2003). Validation of a brief quantitative measure of autistic traits: Comparison of the Social Responsiveness Scale with the Autism Diagnostic Interview-Revised. Journal of Autism \& Developmental Disorders, 33(4), 427.

Constantino, J., \& Todd, R. (2003). Autistic traits in the general population: A twin study. Archives of General Psychiatry, 60(5), 524-530.

Cotugno, A. (2009). Social competence and social skills training and intervention for children with autism spectrum disorders. Journal of Autism \& Developmental Disorders, 39(9), 1268-1277.

Coucouvanis, J. (2005). Super skills. Kansas: Autism Asperger Publishing Co.

Cragar, D., \& Horvath, L. (2003). The application of social skills training in the treatment of a child with Asperger's disorder. Journal of Clinical Case Studies, 2, 34-49.

Danrelle, L. A., Fox, J. J., MacLean, W. E., Jr., \& Kaiser, A. E. (1987). An interbehavioral perspective on parent training for families of developmentally delayed children. In D. H. Ruben \& D. J. Delprato (Eds.), New ideas in therapy: 
Introduction to a interdisciplinary approach (pp. 159-177). New York: Greenwood.

Dawson, G., Meltzoff, A., Osterling, J., \& Rinaldi, J. (1998). Neuropsychological correlates of early symptoms of autism. Child Development, 69(5), 1276-1285.

De los Reyes, A., \& Kazdin, A. (2005). Informant discrepancies in the assessment of childhood psychopathology: A critical review, theoretical framework, and recommendations for further study. Psychological Bulletin, 131(4), 483-509.

Dugard, P., \& Todman, J. (1995). Analysis of pretest post test control group designs in educational research. Educational Psychology, 95(15), 181-199.

Dunlap, G., \& Plienis, A. J. (1988). Generalization and maintenance of unsupervised responding via remote contingencies. In R. H. Homer, G. Dunlap, \& R. L. Koegel (Eds.), Generalization and maintenance: Life-style changes in applied settings (pp. 121-142). Baltimore: Paul H. Brookes.

Eaves, L. C, \& Ho, H. H. (1997). School placement and academic achievement in children with autism spectrum disorders Journal of Developmental and Physical Disabilities, 9, 277-291.

Fein, D., Stevens, M., Dunn, M., Waterhouse, L., Allen, D., Rapin, I., et al. (1999). Subtypes of pervasive developmental disorder: Clinical characteristics. Child Neuopsychology, 5, 1-23.

Feinberg, M. (2002). Using social stories to teach specific social skills to individuals diagnosed with autism. Dissertation Abstracts International, 62, Retrieved from PsycINFO database. 
Fisher, M., \& Meyer, L. (2002). Development and social competence after two years for students enrolled in inclusive and self-contained educational programs. Research and Practice for Persons with Severe Disabilities, 27(3), 165-174.

Fowler, S. A. (1988). The effects of peer-mediated interventions on establishing, maintaining, and generalizing children's behavior changes. In R. H. Horner, G. Dunlap, \& R. L. Koegel (Eds.), Generalization and maintenance: Life-style changes in applied settings (pp. 143-170). Baltimore: Paul H. Brookes.

Frankel, F., Myatt, R., Sugar, C., Whitham, C., Gorospe, C., \& Laugeson, E. (2010). A randomized controlled study of parent-assisted children's friendship training with children having autism spectrum disorders. Journal of Autism \& Developmental Disorders, 40(7), 827-842.

Freeman, B., Del'Homme, M., Guthrie, D., \& Zhang, F. (1999). Vineland adaptive behavior scale scores as a function of age and initial IQ in 210 autistic children. Journal of Autism \& Developmental Disorders, 29(5), 379-384.

Gray, C. (1993). The new social story book - illustrated edition. Arlington, TX: Future Horizons, Inc

Graziano, A. M., \& Diament, D. M. (1992). Parent behavioral training: An examination of the paradigm. Behavior Modification, 16, 3-38.

Gresham, F. M., Sugai, G., \& Horner, R. H. (2001). Interpreting outcomes of social skills training for students with high-incidence disabilities. Teaching Exceptional Children, 67, 331-344.

Gresham, F. M., \& Elliott, S. N. (1990). Social skills rating system. Circle Pines, MN: American Guidance Service. 
Hauck, M., Fein, D., Waterhouse, L., Feinstein, C. (1995). Social initiations by children with autism to adults and other children. Journal of Autism and Developmental Disorders, 25, 579-595

Herschell, A. D., McNeil, C. B., \& McNeil, D. W. (2004). Clinical child psychology's progress in disseminating empirically supported treatments. Clinical Psychology: Science and Practice, 11, 267-288.

Horner, R., Carr, E., Halle, J., McGee, G., Odom, S., \& Wolery, M. (2005). The use of single-subject research to identify evidence-based practice in special education. Exceptional Children, 71(2), 165-179.

Howlin, P. (2000). Outcome in adult life for more able individuals with autism or Asperger syndrome. Autism, 4, 63-83.

Howlin, P., \& Goode, S. (1998). Outcome in adult life for people with autism, asperger syndrome. In F. R. Volkmar (Eds.), Autism and pervasive developmental disorders (pp. 209-241). New York: Cambridge University Press.

Howlin, P., \& Mawhood, L. (2000). Autism and developmental receptive language disorder--a follow-up comparison in early adult life. II: Social, behavioral, and psychiatric outcomes. Journal of Child Psychology \& Psychiatry \& Allied Disciplines, 41(5), 561.

Hwang, B., \& Hughes, C. (2000). The effects of social interactive training on early social communicative skills of children with autism. Journal of Autism and Developmental Disorders, 30(4), 331-343.

Jackson, D. A., Jackson, N. F., \& Bennett, M. L. (1998). Teaching social competence to youth and adults with developmental disabilities. Austin: PRO-ED. 
Kelly, A. (1996). Talkabout. Oxon, UK: Speechmark Publishing Ltd.

Kim, K., \& Van de Wiel, M. (2008). Effects of dependence in high-dimensional multiple testing problems. BMC Bioinformatics, 9114.

Klin, A. (2000). Attributing social meaning to ambiguous visual stimuli in higherfunctioning autism and Asperger syndrome: The social attribution task. Journal of Child Psychology and Psychiatry and Allied Disciplines, 41(7), 831-846.

Klin, A., Jones, W., Shultz, R., \& Volkmar, F. (2003). The enactive mind, or from actions to cognition: Lessons from autism. Philosophical Transactions of the Royal Society of London. Series B, Biological Sciences, 358(1430), 345-360.

Koegel, L., \& Koegel, R. (1995). Current issues in autism; learning and cognition in autism. New York: Plenum Press.

Koegel, R. L., Schreibman, L., Britten, K. R., Burke, J. C., \& O'Neill, R. E. (1982). A comparison of parent training to direct clinic treatment. In R. L. Koegel, A. Rincover, \& A. L. Egel (Eds.), Educating and understanding autistic children (pp. 260-279). Houston: College Hill Press.

Koenig, K., De Los Reyes, A., Cicchetti, D., Scahill, L., \& Klin, A. (2009). Group intervention to promote social skills in school-age children with pervasive developmental disorders: Reconsidering Efficacy. Journal of Autism \& Developmental Disorders, 39(8), 1163-1172.

Konstantareas, M., \& Stewart, K. (2006). Affect regulation and temperament in children with autism spectrum disorder. Journal of Autism and Developmental Disorders, $36(2), 143-154$. 
Kraemer, H., Measelle, J., Ablow, J., Essex, M., Boyce, W., \& Kupfer, D. (2003). A new approach to integrating data from multiple informants in psychiatric assessment and research: Mixing and matching contexts and perspectives. The American Journal of Psychiatry, 160, 1566-1577.

Krasny, L., Williams, B. J., Provencal, S., \& Ozonoff, S. (2003). Social skills interventions for the autism spectrum: Essential ingredients and a model curriculum. Child and Adolescent Psychiatric Clinics of North America, 12, 107122.

Krantz, P., \& McClannahan, L. (1993). Teaching children with autism to initiate to peers: Effects of a script-fading procedure. Journal of Applied Behavior Analysis, 26(1), 121-32.

Kroeger, K. A., Schultz, J. R., \& Newsom, C. (2007). A comparison of two groupdelivered social skills programs for young children with autism. Journal of Autism and Developmental Disorders, 37, 808-817.

Laugeson, E., Frankel, F., Mogil, C., \& Dillon, A. (2009). Parent-assisted social skills training to improve friendships in teens with autism spectrum disorders. Journal of Autism \& Developmental Disorders, 39(4), 596-606.

Leblanc, L., Richardson, W., \& Burns, K. (2009). Autism spectrum disorder and the inclusive classroom: Effective training to enhance knowledge of ASD and evidence-based practices. Teacher Education and Special Education, 32(2), 166179. 
Lopata, C., Thomeer, M. L., Volker, M. A., \& Nida, R. E. (2006). Effectiveness of a cognitive-behavioral treatment on the social behaviors of children with Asperger Disorder. Focus on Autism and Other Developmental Disabilities, 21, 237-244.

Lord, C., Wagner, A., Rogers, S. Szatmari P., Aman M., \& Charman T., et al. (2005). Challenges in evaluating psychosocial interventions for autistic spectrum disorders. Journal of Autism and Developmental Disorders, 35(6), 695-708.

Lovaas, O. I., Koegel, R. L., Simmons, J.Q., \& Long, J. S. (1973). Some generalization and follow-up measures on autistic children in behavior therapy. Journal of Applied Behavior Analysis, 6, 131-166.

Mazurik-Charles, R., \& Stefanou, C. (2010). Using paraprofessionals to teach social skills to children with autism spectrum disorders in the general education classroom. Journal of Instructional Psychology, 37(2), 161-169.

McAfee, J. (2002). Navigating the social world. Arlington, TX: Future Horizons, Inc. McConnell, S. R. (2002). Interventions to facilitate social interaction for young children with autism: Review of available research and recommendations for educational intervention and future research. Journal of Autism and Developmental Disorders, $32,351-372$.

Mesibov, G. B. (1984). Social skills training with verbal autistic adolescents and adults: A program model. Journal of Autism and Developmental Disorders, 14, 395-403.

Murray, D., Ruble, L., Willis, H., \& Malloy, C. (2007). Congruency between caregiver and teacher report of social skills in children with autism spectrum disorder. Manuscript submitted for publication. 
Myles, B. (2003). Behavioral forms of stress management for individuals with Asperger syndrome. Child and Adolescent Psychiatric Clinics of North America, 12, 123141.

National Research Council, Committee on Educational Interventions for Children with Autism. (2001). Educating children with autism. Washington, DC: National Academy Press.

Odom, S. L., Brantlinger, E., Gersten, R., Horner, R. H., Thompson, B., \& Harris, K. R. (2005). Research in special education: Scientific methods and evidence-based practices. Exceptional Children, 71, 137-148.

Ozonoff, S., \& Miller, J. N. (1995). Teaching theory of mind: A new approach to social skills training for individuals with autism. Journal of Autism and Developmental Disorders, 25, 415-433.

Piven, J., Harper, J., Palmer, P., Arndt, S. (2006). Course of behavioral change in autism: a retrospective study of high-IQ adolescents and adults. Journal of American Academy Child and Adolescent Psychiatry;35: 523-9.

Polster, R. A., Dangel, R. E, \& Rasp, R. (1986-1987). Research in behavioral parent training in social work: A review. Special issue: Progress in behavioral social work. Journal of Social Service Research, 10, 37-51.

Provencal, S. L. (2003). The efficacy of a social skills training program for adolescents with autism spectrum disorders (Unpublished doctoral dissertation). University of Utah. 
Quill, A. (1997). Instructional considerations for young children with autism: The rationale for visually cued instruction. Journal of Autism and Developmental Disorders, 27, 697-714.

Ramey, C. T., \& McPhee, D. (1986). Developmental retardation: A systems theory perspective on risk and preventative intervention. In D. C. Farran \& J. D. McKinney (Eds), Risk in intellectual and psychosocial development ( $\mathrm{pp}$ 61-81). Orlando, FL: Academic Press.

Rao, P., Beidel, D., \& Murray, M. (2008). Social skills interventions for children with Asperger's syndrome or high-functioning autism: A review and recommendations. Journal of Autism and Developmental Disorders, 38, 353-361.

Rodrigue, R., Morgan, S., \& Geffken, G. (1991). A comparative evaluation of adaptive behavior in children and adolescents with autism, Down syndrome, and normal development. Journal of Autism and Developmental Disorders 21(2), 187-196.

Rogers, S. J. (2000). Interventions that facilitate socialization in children with autism. Journal of Autism and Developmental Disorders, 30, 399-409.

Rose, R., \& Anketell, C. (2009). The benefits of social skills groups for young people with autism spectrum disorder: A pilot study. Child Care in Practice, 15(2), $127-$ 144.

Ruble, L., Willis, H., \& Crabtree, V. M. (2008). Social skills group therapy for autism spectrum disorders. Clinical Case Studies, 7(4), 287-300.

Ruble, L., \& Dalrymple, N. (1996). An alternative view of outcome in autism. Focus on Autism \& Other Developmental Disabilities, $11(1), 3$. 
Rydell, A. M., Hagekull, B., \& Bohlin, G. (1997). Measurement of two social competence aspects in middle childhood. Developmental Psychology, 33, 824 833.

Sailor, W., Goetz, L., Anderson, J., Hunt, P., \& Gee, K. (1988). Research on community intensive instruction as a model for building functional, generalized skills. In R. H. Homer, G. Dunlap, \& R. L. Koegel (Eds.), Generalization and maintenance: Life-style changes in applied settings (pp. 67-98). Baltimore: Paul H. Brookes.

Scattone, D., Wilczynski, S., Edwards, R., \& Rabian, B. (2002). Decreasing disruptive behaviors of children with autism using social stories. Journal of Autism \& Developmental Disorders, 32(6), 535.

Schaefer, C. E., \& Briesmeister, J. M. (1989). Handbook of parent training: Parents as co-therapists for children's behavior problems. New York: Wiley.

Schreibman, L. (1997). Theoretical perspectives on behavioral intervention for individuals with autism. In D. J. Cohen \& F. R. Volkmar (Eds.), Handbook of autism and pervasive developmental disorders, 2nd ed., (pp. 920-933). New York: Wiley.

Seifer, R., Sameroff, A., Baldwin, C., \& Baldwin, A. (1992). Child and family factors that ameliorate risk between 4 and 13 years of age. Journal of the American Academy of Child and Adolescent Psychiatry, 31(5), 893-903.

Sigman, M., \& Ruskin, E. (1999). Continuity and change in the social competence of children with autism, Down syndrome, and developmental delays. Monographs of the Society for Research in Child Development, 64, 114. 
Simpson, R. L. (2005). Evidence-based practices and students with autism spectrum disorders. Focus on Autism and Other Developmental Disabilities, 20, 140-149.

Simpson, R., Myles, B., Sasso, G., Kamps, D., \& Council for Exceptional Children, R. (1997). Social Skills for Students with Autism. Second Edition. CEC MiniLibrary: Working with Behavioral Disorders.

Smith, T., Scahill, L., Dawson, G., Guthrie, D., Lord, C., \& Odom, S., et al. (2006). Designing research studies on psychosocial interventions in autism. Journal of Autism and Developmental Disorders, 37, 354-366.

Solomon, M., Goodlin-Jones, B. L., \& Anders, T. F. (2004). A social adjustment enhancement intervention for high functioning autism, asperger's syndrome, and pervasive developmental developmental disorder NOS. Journal of Autism and Developmental Disorders, 34, 649-668.

Stichter, J., Randolph, J., Gage, N., \& Schmidt, C. (2007). A review of recommended social competency programs for students with autism spectrum disorders. Exceptionality, 15(4), 219-232.

Stone, W., Ruble, L., Coonrod, E., Hepburn, S., \& Pennington, M. (2002). TRIAD Social Skills Assessment Manual. Available at 2100 Pierce Ave., Medical Center South, Rm. 426, Nashville, TN 37232.

Tantam, D. (2003). The challenge of adolescents and adults with asperger syndrome. Child Adolescence and Psychiatric Clinics of North America, 12, 143-163.

Tager-Flusberg, H., Paul, R., \& Lord, C. (2003). Language and communication in autism. In F. Volkmar, R. Paul, A. Klin, \& D. Cohen (Eds.), Handbook of autism and 
pervasive developmental disorders, Vol. 1: Diagnosis, development, neurobiology, and behavior, 3rd ed., (pp. 335-364). Hoboken, NJ: Wiley.

Tauber, R., Wallace, C.J., \& Lecomte, T. (2000). Enlisting indigenous community supporters in skills training programs for persons with severe mental illness. Psychiatric Services, 51, 1428-1432.

Tiedemann, G. L., Georgia, L., \& Johnston, C. (1992). Evaluation of a parent training program to promote sharing between young siblings. Behavior Therapy, 23, 299318.

Trimarchi, C. L. (2004). The implementation and evaluation of a social skills training program for children with asperger syndrome. (Unpublished doctoral dissertation). University at Albany, State University of New York.

Tse, J., Strulovitch, J., Tagalakis, V., Meng, L., \& Fombonne, E. (2007). Social skills training for adolescents with asperger syndrome and high functioning autism. Journal of Autism and Developmental Disorders, 37, 1960-1968.

US Department of Education. (2003). Twenty-fifth annual report to congress on the implementation of the IDEA act. Washington, DC: Author.

Volkmar, F., Paul, R., Klin, A., \& Cohen, D. (2005). Handbook of autism and pervasive developmental disorders, Vol. 2: Assessment, interventions, and policy (3rd ed.). Hoboken, NJ: John Wiley \& Sons.

Webster-Stratton, C., \& Hammond, M. (1990). Predictors of treatment outcome in parent training for families with conduct problem children. Behavior Therapy, 21, 319337. 
Webster-Stratton, C., Hollinsworth, T, \& Kolpacoff, M. (1989). The long-term effectiveness and clinical significance of three cost-effective training programs for families with conduct problem children. Journal of Consulting and Clinical Psychology, 57, 550-553.

Weiss, M. J., \& Harris, S. L. (2001). Teaching social skills to people with Autism. Behavior Modification, 25, 785-802.

Whalen, C., \& Schreibman, L. (2003). Joint attention training for children with autism using behavior modification procedures. Journal of Child Psychology \& Psychiatry \& Allied Disciplines, 44(3), 456-468.

White, S. W., Keonig, K., \& Scahill, L. (2007). Social skills development in children with autism spectrum disorders: A review of the intervention research. Journal of Autism and Developmental Disorders, 37, 1858-1868. 


\section{CURRICULUM VITAE}

NAME: $\quad$ Grace Mathai

ADDRESS: University of Louisville

College of Education and Human Development

Educational and Counseling Psychology Department

Louisville, KY 40292

EDUCATION:

Bachelor of Arts, Psychology

Bangalore University, India

1984-1989

Masters in Clinical Psychology

Bangalore University, India

1989-1993

Doctoral Candidate in Counseling Psychology

University of Louisville

2006-present

AWARDS:

- International Meeting for Autism Research, (2008) received Travel award to present scientific paper on Autism in London, England.

- Awarded National Merit scholarship for Masters Program (19891991).

- Ranked No. 3, in Master's Program

- Ranked No. 6, in Bachelor of Arts Program

PROFESSIONAL SOCIETIES:

- Licensed with the Kentucky Board of Psychologists as Licensed Psychological Associate.

- Member of Kentucky Psychological Association

- Member of International Meeting for Research in Autism

JOURNAL PUBLICATIONS:

- Ruble, L. A. \& Mathai, G (2010) COMPASS: Finding direction for individuals with autism spectrum disorders. International Public Health Journal,2(1) 51-56. 
- Mathai, G. \& Ruble, L. A. (2008) Implementing a social skills group for children with autism spectrum disorders. Journal of Psychological Practice 15: 135-156.

- Nounopoulos, A., Mathai, G., \& Ruble, L. A. (2008) An Ecological Approach to Outpatient Behavior Management Services for Children with Autism Spectrum Disorders. Journal of Psychological Practice 15: $178-216$.

- Sokhadze, E. M., El-Baz, A., Baruth, J., Mathai, G., Sears, L., \& Casanova, M.(2008) Effects of low frequency repetitive transcranial magnetic stimulation on gamma frequency oscillations and event related potentials during processing of illusory figures in autism. Journal of Autism and Developmental Disorders 39: 619-34.

- Sokhadze E, El-Baz, A, Baruth J, Mathai G, Sears L, Casanova M (2009). Event-related potential study of novelty processing abnormalities in autism. Applied Psychophysiology and Biofeedback, 34: $37-51$.

BOOK CHAPTERS AND MONOGRAPHS:

- Ruble, L., Mathai, G., Tanguay, P., \& Josephson, A., Psychosocial treatment of Asperger's Disorder. In J. Rausch (Ed). Asperger's Disorder. Informa Healthcare. NY. NY.

\section{RESEARCH PRESENTATIONS:}

- Mathai, G, Sears, L \& Ruble, L. (2010). Adaptive functioning and cognitive development in young children with Autism at International Conference on Autism Research, Pittsburg, May $20^{\text {th }}$.

- Mathai, G, Sears, L \& Ruble, L. (2009). Autism severity and its impact on cognitive development in young children with Autism at International Conference on Autism Research, Chicago, May $8^{\text {th }}$.

- Sokhadze, E., Tasman, A., Baruth, J., Sears, L., Mathai, G., \& Casanova, M. (2009) Repetitive TMS affects EEG gamma and ERP during perceptual processing in autism. Presented at the annual meeting of Association for Applied Psychophysiology \& Biofeedback, Albuquerque, NM, April 2-4.

- Sokhadze, E., El-Baz, A., Tasman, A., Baruth, J., , Mathai, G., Sears, L. \& Casanova, M. (2009) Electrocortical and behavioral outcomes of novel experimental trial of repetitive magnetic stimulation in autism. Presented at International meeting for Autism Research, Chicago, IL, May 7-9.

- Baruth, J., Mansoor, M. Mathai, G. Sears, L., Husk, M. Sokhadze, E. Casanova, M. (2009) The Effects of Transcranial Magnetic Stimulation on Novelty Processing in Autism .Presented at the annual meeting of Association for Psychological Sciences, San Francisco, CA, May 22-25. 
- Mathai, G., Hardesty, P., \& Ruble, L. (2008) Autism Spectrum Disorders: Referral concerns across the developmental life span. Poster presented at International Conference on Autism Research, London, May 16th.

- Mathai, G., Ruble, L. \& Flores, P. (2007). Efficacy of a Social Skills Camp with students with Autism at International Conference on Autism Research, Seatlle, May 5 th

- Sokhadze, T., Tasman, A., Baruth, J., Sears, L., Mathai, G. \& Casanova, M.(2008) Dense-array event-related potential study of novelty processing abnormalities in autism spectrum disorders. Presentation at the annual Association for Applied Psychophysiology \& Biofeedback Meeting, Daytona beach, FL., May 13-16.

- Sokhadze, T., Singh, S., El-Baz, A., Mathai, G., Sears, L., \& Casanova, M. (2007) Evoked and induced gamma frequency oscillations and coherence in EEG, and Event-Related Potential abnormalities during processing of illusory figures in Autism Spectrum Disorders. Presented at Research!Louisville conference, October 16-18.

- Sokhadze, E., Singh, S., El-Baz, A., Mathai, G., Sears. L., Casanova, M. (2007) Evoked and induced gamma frequency oscillations, interhemispheral coherence and event-related potential abnormalities during processing of illusory figures in Autism Spectrum Disorders. Presented at the ISNR meeting, San Diego, September 6-9.

- Sokhadze, E., Singh, S., El-Baz, A., Mathai, G.,Sears, L., \& Casanova, M. (2007) Induced gamma oscillations, ERP, and coherence abnormalities during processing perceptual binding in autism. Presented at the $19^{\text {th }}$ annual meeting of the Association for Psychological Sciences, Washington, DC, May 24-29.

- Sokhadze, T., Casanova, M., Mathai, G., \& Ruble, L. (2006) Eventrelated potential study of emotional and attentional processing deficits in high-functioning children with autism: A pilot study. Presented at the $14^{\text {th }}$ annual conference of ISNR, Atlanta, GA, September 7-10. 